\title{
Caracterización de la Cultura Organizacional en las MiPyMEs para Impulsar el Emprendimiento de alto Impacto en el Valle del Mezquital.
}

Characterization of the Organizational Culture in MSMEs to Promote High Impact Entrepreneurship in the Mezquital Valley.

Recepción: 2 de Septiembre del 2016

Aceptación: 7 de Octubre del 2016

Publicación: 16 de Diciembre del 2016
Irasema Linares Medina

Julio Márquez Rodríguez

Esther Botho Clemente
El emprendimiento de alto impacto, también llamado emprendimiento transformador (Lerner y Schoar, 2010), se distingue principalmente por buscar no solo una rentabilidad económica, sino lograr un verdadero impacto social, asegurando una contribución positiva con el medio ambiente. La caracterización de la cultura organizacional en las Micro, Pequeñas y Medianas Empresas (MiPyMEs) juega un papel preponderante para su desarrollo y consolidación, particularmente cuando se trata de promover en las MiPyMEs su alineamiento hacia el emprendimiento de alto impacto, ya que diversos estudios han demostrado que los rasgos de cultura organizacional son determinantes para el éxito o fracaso de las empresas. La presente propuesta, realizada con el apoyo del Instituto Nacional del Emprendedor, promueve el desarrollo de un estudio de cultura organizacional aplicado a una muestra de 80 MiPyMEs ubicadas en la región conocida como: Valle del Mezquital, en el Estado de Hidalgo, México; cuyo contexto socioeconómico y cultural es especial, ya que cuenta con más del $30 \%$ de población indígena que, además de contar con arraigadas costumbres heredadas de un pasado y presente de pobreza económi$\mathrm{ca}$, presenta un singular fenómeno migratorio hacia los Estados Unidos.
El propósito del estudio es determinar el tipo de cultura organizacional dominante en el marco del modelo de Cameron y Quinn (1999) e identificar, a través de la adecuación de un modelo de diagnóstico y de la aplicación de herramientas de recopilación de datos, cuáles son los elementos culturales que favorecen o limitan la existencia de emprendimientos de alto impacto en las MiPyMEs de esta región y, a partir de los resultados, proponer un conjunto de estrategias que permita impulsar este tipo de emprendimientos, contribuyendo así al desarrollo económico y social del Valle del Mezquital.

Palabras Clave: Alto impacto, emprendimiento, MiPyMEs, Cultura organizacional, Valle del Mezquital.

Keywords: High impact, entrepreneurship, MSMEs, Organizational culture, Valle del Mezquital. 


\section{Intodución}

La habilidad que las empresas desarrollen para poder adaptarse a los constantes cambios originados por un entorno global y por las tendencias sociales y tecnológicas, constituye una condición de gran importancia para mantener e incrementar su competitividad a lo largo del tiempo. Para ello, estas entidades requieren más que nunca potencializar las capacidades y competencias de los colaboradores que las integran y alinear su cultura organizacional hacia el logro de sus objetivos clave.

De acuerdo con Toca y Carrillo (2009), la cultura de un pueblo se compone por el conjunto de patrones compartidos y heredados por la sociedad, que sirven de guía de comportamiento, generan pautas de conducta y dan al individuo sentido de pertenencia e identidad. De manera similar, la cultura de una organización, le permite diferenciarse de cualquier otra, brindando a sus miembros identificación y sentido de pertenencia. A pesar de la existencia de un amplio conjunto de definiciones de la cultura organizacional, Schein (2010) considera que existe un consenso general en reconocerla como el conjunto de patrones y significados que son compartidos por los miembros de una organización. La identificación y la gestión adecuada de los principales componentes de la cultura organizacional, puede contribuir al logro de mejores condiciones para la consecución de los objetivos de las empresas, sobre todo cuando se trata de MiPyMEs, ya que este tipo de organizaciones, dado su tamaño y estructura, basan en mayor medida su permanencia y desempeño, en las cualidades de su cultura.

Es sabido que las MiPyMEs en México constituyen una parte fundamental de la economía nacional por el número de empleos y la actividad económica que generan.

De acuerdo con el INEGI (2010) el $99.8 \%$ de los 4 millones 15 mil unidades empresariales que existen en México son MiPyMEs mismas que generan el $52 \%$ del Producto Interno Bruto en el país. De acuerdo con el Plan Nacional de Desarrollo 2013-2018, en México las MiPyMEs contribuyen con el $73 \%$ de los empleos del país, lo cual significa casi 20 millones de puestos laborales. Sin embargo, el desconocimiento del entorno, la improvisación, la selección de personal inadecuado y sobre todo el manejo empírico del negocio, generan, de acuerdo con Rizo (2014), que un $87 \%$ de las MiPyMEs en México fracasen. Esta problemática tiene su origen en gran medida en la nula diferenciación entre las finanzas personales y empresariales, en su escasa gestión de la calidad, en la falta de financiamientos adecuados y oportunos, y particularmente en una deficiente administración y un mal control financiero, condiciones estrechamente vinculadas con la cultura organizacional. Es por ello, resulta pertinente identificar los rasgos culturales que permitan generar las condiciones que contribuyan a mejorar el establecimiento, crecimiento y consolidación de las MiPyMEs en México.

El emprendimiento de alto impacto, se distingue por poseer un modelo de negocios con ventajas sostenibles y escalables, generadoras de empleos de calidad, que crecen de manera rentable, rápida y sostenida.

contar con un equipo multidisciplinario para potencializar la colectividad, proponer soluciones sencillas y efectivas, optimizar el uso de la tecnología disponible, tener enfoque global, ser rentable económicamente y ambientalmente sostenible, tener la capacidad de crecer, ser innovadora, propiciar impacto social y; crear valor para sus clientes. Además, un emprendimiento de alto impacto tiene un potencial realizable de crecimiento gracias a una ventaja competitiva, que puede ser tecnológica 0 no. 
Los emprendimientos de alto impacto, a diferencia los denominados: proyectos de supervivencia o de autoempleo, que son comunes en las MiPyMEs en México, operan bajo una lógica de acumulación generando ingresos muy por encima de los niveles de subsistencia del propietario, mismos que son reinvertidos en el desarrollo del emprendimiento. Estas características demandan sin duda de una cultura organizacional que permita el enfoque de largo plazo y genere las condiciones propicias para alcanzar las ventajas de este tipo de emprendimientos.

El Valle del Mezquital, porción del Estado de Hidalgo localizada a $160 \mathrm{~km}$ al noroeste de la Ciudad de México, constituye una región muy amplia y de gran importancia ecológica, económica, social, histórica y cultural, donde se desarrolla una población que desempeña diversas actividades productivas de especial relevancia para la economía global de la entidad y áreas circunvecinas. Esta región se caracteriza porque un alto porcentaje de la población es de origen indígena ya que en este territorio se encuentra asentada la etnia otomí o hñahñu.

\section{Su heterogeneidad ambiental,} socioeconómica y cultural han influido para que en el Valle del Mezquital exista un gran potencial de recursos de los cuales dependen las poblaciones ahí establecidas.

El Valle del Mezquital incluye 28 municipios, entre los más importantes se encuentran: Actopan, Alfajayucan, El Cardonal, Chilcuautla, Ixmiquilpan, Nicolás Flores, San Salvador, Santiago de Anaya, Tasquillo y Zimapán, algunos de ellos catalogados por el CONAPO (2011) como municipios con alta marginación.
De acuerdo con la Comisión Nacional para el Desarrollo de los Pueblos Indígenas, en el Valle del Mezquital no existe correspondencia entre la magnitud de lo que se produce y los niveles de bienestar de la población, ya que las condiciones climatológicas adversas, los bajos niveles de producción, la mala organización social, la escasa utilización de tecnología, elrezago educativo y la aplicación de modelos de producción ajenos a las condiciones ecológicas y socioeconómicas, han traído como consecuencia además de una baja productividad, un deterioro ambiental acentuado, el agotamiento de los recursos naturales y particularmente un fenómeno migratorio que contribuye a la ausencia de organización para la producción, transformación y comercialización, limitando el desarrollo y convirtiendo a la región en un sitio de marginación, pobreza e injusticia social (CDI, 2009).

Las anteriores condiciones, aunadas al incremento de la migración hacia Estados Unidos y el aumento en el envío de remesas hacia esta región, han generado que en los últimos años se haya detonado la creación de proyectos emprendedores que principalmente han tenido como característica buscar el autoempleo y la subsistencia de quien emprende, propiciando una alta volatilidad, una gran vulnerabilidad y escasa consolidación de las MiPyMEs.

Derivado de lo anterior, se ha reconocido la necesidad de identificar los principales rasgos de la cultura organizacional de las MiPyMEs del Valle del Mezquital, con la finalidad de determinar: ¿̇Cuáles rasgos de la cultura organizacional pueden impulsar el emprendimiento de alto impacto? El estudio propuesto es de tipo exploratorio y pretende que sus resultados contribuyan a establecer una serie de recomendaciones dirigidas a impulsar en las MiPyMEs de la región, condiciones de cultura organizacional que favorezcan la existencia de empresas duraderas, sostenibles y con un alto impacto social. 


\section{Identificación del problema}

El problema que se ha identificado, es la alta volatilidad de las MiPyMEs en el Valle del Mezquital y su escasa o nula alineación hacia el emprendimiento de alto impacto. De acuerdo a la OCDE (2005), en México el $90 \%$ de las MiPyMEs no alcanza a cumplir los 5 años de operación, además la mayoría de los emprendimientos que surgen en esta región se orientan al autoempleo y a buscar la subsistencia económica del propietario, siendo el principal medio de financiamiento las remesas que los migrantes internacionales envían a sus familias.

Estas condiciones impiden el desarrollo de emprendimientos de alto impacto: rentables, sostenibles, escalables, durables, social y ambientalmente pertinentes.

Esta realidad pone de manifiesto la necesidad de identificar alternativas que motiven el emprendimiento de alto impacto para favorecer el desempeño y de las MiPyMEs y evitar su extinción. Una alternativa es la adopción de las características de una cultura organizacional que les permita generar emprendimientos de alto impacto y tener mayores posibilidades de permanencia y consolidación

Nota. Tope máximo combinado $=($ Núm. de trabajadores x 10\% $)+($ ventas anuales x 90\%). Fuente: INEGI (2009). Estratificación de los establecimientos. 
Para México las MiPyMEs constituyen un eslabón fundamental e indispensable para el crecimiento económico del país, ya que México cuenta con una importante base de este tipo de empresas claramente más sólida que muchos otros países del mundo (PROMEXICO, 2014). En este sentido, las MiPyMEs en México tienen dos grandes virtudes: absorben a una porción importante de la población económicamente activa del país,ysu modo de operación puedeadaptarse más fácilmente a las nuevas tecnologías y tendencias empresariales. Las MiPyMEs contribuyen ampliamente al desarrollo de la actividad comercial regional, al explotar los recursos propios de cada entidad y emplear a la población local. Sin embargo, se han identificado grandes debilidades en este tipo de empresas, entre las más destacadas se encuentra que no reinvierten sus utilidades para la mejora de equipo o técnicas de producción, que por su naturaleza carecen de personal especializado por lo que no ofrecen sueldos competitivos; y que al tener la mayoría de ellas un origen familiar, solo se orientaron hacia supervivencia sin prestar atención a los factores que les permiten un crecimiento sostenido.

\section{La cultura organizacional}

Existe un amplio conjunto de definiciones de la cultura organizacional y diferentes posturas para su análisis, derivadas de la diferencia en la perspectiva utilizada para su interpretación, puede reconocerse un consenso general en identificarla como el conjunto de patrones y significados que son compartidos por los miembros de una organización, sirven de guía de comportamiento, proporcionan al colaborador sentido de pertenencia e identidad con la organización, y permiten a la organización diferenciarse de cualquier otra. La cultura de una organización constituye un factor determinante en la búsqueda de la mejora de su desempeño en virtud de que se relaciona directamente con los resultados y la eficiencia, así como con la identidad, el compromiso y la calidad del trabajo de sus colaboradores.

Schein (2010) propuso un marco de referencia integrado por tres dimensiones básicas que permiten agrupar los distintos elementos de la cultura organizacional. La primera, la constituyen el conjunto de premisas que impactan contundentemente en la mayoría de pensamientos y acciones de la organización, es decir, los valores, las ideologías, los supuestos y el conocimiento. La segunda, se integra por las creencias estratégicas, mismas que se sustentan en las convicciones y certezas de los líderes organizacionales. La tercera, incorpora todo tipo de prácticas, el lenguaje, los símbolos, las historias, los rituales, las rutinas, los estándares, las convenciones y las costumbres.

\section{La cultura organizacional en las MiPyMEs}

Las MiPyMEs como cualquier organización, también tienen manifestaciones culturales que deben ser analizadas y gestionadas para lograr alinear los elementos de su cultura organizacional al logro de sus objetivos y a la mejora desu desempeñoy productividad para favorecer su permanencia y consolidación.

Para Prahalad y Hamel (1990) la cultura organizacional forma parte de los recursos y capacidades de la empresa, ya que genera activos intangibles que resultan estratégicos para favorecer la posición competitiva de la organización.

Dichos activos intangibles incluyen el prestigio, la imagen, la reputación, así como las habilidades y las capacidades de los colaboradores que integran la organización. 
Dichos activos intangibles incluyen el prestigio, la imagen, la reputación, así como las habilidades y las capacidades de los colaboradores que integran la organización. Esparza, García y Gómez (2010) consideran que la cultura organizacional es un recurso intangible que influye en la gestión estratégica de las MiPyMEs y que, a través de los valores de la organización, es posible generar ventajas competitivas e influir en su comportamiento estratégico.

\section{El modelo de efectividad organizacional: Competing Values Framework}

El presente estudio propone como referente para identificar el tipo de cultura organizacional dominante de las MiPyMEs, el modelo desarrollado por Cameron y Quinn (1999) denominado: Competing Values Framework, el cual se basa en el establecimiento de dos dimensiones, la primera que contrasta los criterios de efectividad que enfatizan la flexibilidad, la discreción y el dinamismo frente a los criterios de estabilidad, orden y control; y la segunda que confronta los criterios de efectividad que favorecen la orientación interna y la integración, en contraste con los criterios que enfatizan la orientación externa, la rivalidad y la diferenciación. La unión de estas dos dimensiones generan cuatro cuadrantes que representan un conjunto de indicadores de efectividad organizacional que identifican a tipo específico del cultura organizacional.
Figura 1. Modelo Competing Value Framework. Fuente: Cameron, K. y Quinn, R. (1999). Diagnosing and Changing Organizational Culture.

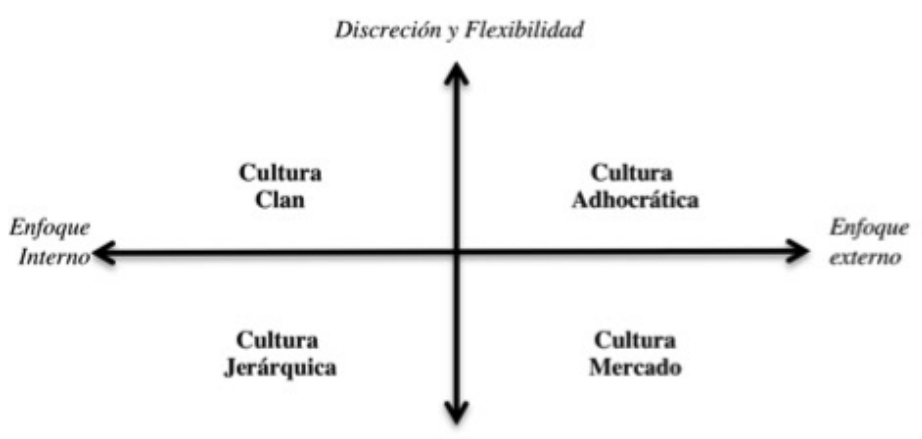

Los cuatro cuadrantes que propone el modelo Competing Value Framework corresponden a cuatro tipos de cultura organizacional, nombrados de acuerdo asu característica más relevante. En el cuadrante superior izquierdo se encuentra la cultura de Clan, identificada para organizaciones que tienen gran similitud con una familia y que constituyen lugares armoniosos para trabajar, en los cuales los directivos se aprecian como mentores y los colaboradores comparten valores como la cohesión, el trabajo en equipo, la lealtad y el cuidado de las tradiciones, dando como resultado un marcado énfasis en el desarrollo del personal y en la satisfacción del cliente.

La cultura Adhocrática, ubicada en el cuadrante superior derecho, identifica organizaciones que cuentan con un ambiente laboral innovador, creativo y dinámico, mismo que estimula las iniciativas individuales, el crecimiento, la incorporación de nuevos productos o servicios y el logro de mayores utilidades a través de la innovación y el espíritu emprendedor. En el cuadrante inferior izquierdo se encuentra la cultura Jerárquica, en la que se destaca la organización burocrática, la existencia de estructuras, políticas y procedimientos formales. 
Este tipo de cultura promueve la coordinación y el control para el logro de la cohesión, estabilidad y funcionamiento eficaz de la organización. Finalmente, la cultura de Mercado identifica a las organizaciones que se orientan hacia la atención de sus grupos externos de interés más que a su contexto interno, para obtener resultados mediante un trabajo orientado al logro de objetivos y sustentado en colaboradores competitivos y líderes exigentes, que promueven el posicionamiento y la estabilidad de la organización.

\section{El emprendimiento de alto impacto}

De acuerdo con Martínez et al (2014) el concepto de emprendimiento surgió en el siglo XVI de la palabra francesa entreprendre utilizado para referirse al acto de gestionar una empresa. Fue Richard Cantillon quien introdujo el concepto de entrepreneur para designar a aquel individuo que asumía el riesgo derivado de una actividad con la esperanza de recompensa en el futuro. El economista austriaco Joseph Schumpeter considera que un emprendedor es una persona que destruye el actual orden económico, mediante la creación de nuevos productos o servicios nunca antes vistos. (Martínez-Estrada, 2014).

Por su parte, Lozano (2013) establece que el emprendimiento es una manera de pensar y actuar orientada hacia la creación de riqueza. Agrega que es una forma de pensar, razonar y actuar que se centra en las oportunidades, planteada con visión global y llevada a cabo mediante un liderazgo equilibrado y la gestión de un riesgo calculado. El resultado del emprendimiento es la creación de valor que beneficia a la empresa, la economía y la sociedad.

El emprendimiento de alto impacto, también llamado emprendimiento transformador
(Lerner y Schoar, 2010), se distingue principalmente por buscar no solo una rentabilidad económica, sino lograr un verdadero impacto social, asegurando una contribución positiva con el medio ambiente. Posee un modelo de negocios con ventajas sostenibles y escalables, generadoras de empleos de calidad, que crecen de manera rentable, rápida y sostenida. Para Díaz (2014) una iniciativa empresarial de alto impacto cuenta con un equipo multidisciplinario, propone soluciones sencillas y efectivas, aprovecha la tecnología disponible, cuenta con un enfoque global, es rentable económicamente y sostenible ambientalmente, tiene capacidad de crecimiento, es innovadora, propicia un impacto social y crear valor para sus clientes. De esta manera, el emprendimiento de alto impacto es un mecanismo idóneo para la generación de riqueza y el mejoramiento del tejido productivo de las regiones del país, como motor de competitividad, inversión y desarrollo.

La empresa consultora Endeavor a través de su Centro para el Emprendimiento de Alto Impacto en conjunto con Global Entrepenurship Monitor (Endeavor, 2011) han identificado, a través de diversas encuestas y estudios, un conjunto de características y atributos de asociados a los emprendimientos de alto impacto:

Sus dueños cuentan con una carrera universitaria y la mayoría con un posgrado

Generalmente los propietarios trabajan en asociación con otros emprendedores.

Tienen poco miedo al fracaso

Inician su emprendimiento por que identifican oportunidades de negocio y no porque no tengan otra opción laboral

Una vez que tiene éxito comercial, promueven a otros emprendedores

Son significativamente propensos a proporcionar fondos a los miembros de la familia, en lugar de a sus amigos o 
compañeros de trabajo para iniciar algún emprendimiento.

Son significativamente propensos a proporcionar fondos a los miembros de la familia, en lugar de a sus amigos o compañeros de trabajo para iniciar algún emprendimiento.

- Se encuentran motivados por lograr su independencia económica y por incrementar sus ingresos personales

- A diferencia de la población en general, creen que poseen los conocimientos para iniciar un negocio y por ello tienen menos miedo al fracaso.

En el informe titulado Nature or nurture? Decoding the DNA of the Entrepreneur, (Ernst \& Young, 2012) se establece que los empresarios se hacen, no nacen, y que muy a menudo comparten una combinación similar de comportamientos y actitudes. Dado que los proyectos empresariales son considerados como una importante fuente de crecimiento económico y creación de empleo para los países, es fundamental identificar qué hace una mentalidad emprendedora. Algunas de las conclusiones que se derivan de este informe son: nacen.

Los emprendedores se hacen, no

No existe un gen empresarial pero la mayoría de emprendedores inician a una edad joven su emprendimiento.

- La mayoría de emprendedores fueron empleados alguna vez.

- El emprendimiento es rara vez una decisión de una sola vez.

- El financiamiento, los recursos humanos y el saber hacer son los mayores obstáculos para el éxito empresarial.

- Es esencial conformar equipos de trabajo que combinen conocimientos técnicos con habilidades de negocios porque es muy raro encontrar ambas habilidades de manera individual.
Los emprendedores exitosos poseen fuertes rasgos de control interno y aprecian oportunidades donde otros ven disrupción.

La cultura tiene una fuerte influencia en la toma de riesgos y la tolerancia al fracaso de los emprendedores.

Los emprendedores comparten rasgos comunes.

El informe indica que los líderes empresariales exitosos asocian el éxito de su emprendimiento con: su experiencia como empleado, su educación, sus mentores, el apoyo familiar y la presencia de socios en su emprendimiento. Finalmente, el modelo de emprendedor que propone Ernst \& Young (2011), describe 10 características esenciales : Visión, Pasión, Integridad, Colaboración, Innovación, Liderazgo, Calidad, Enfoque en el cliente, Flexibilidad y Resiliencia

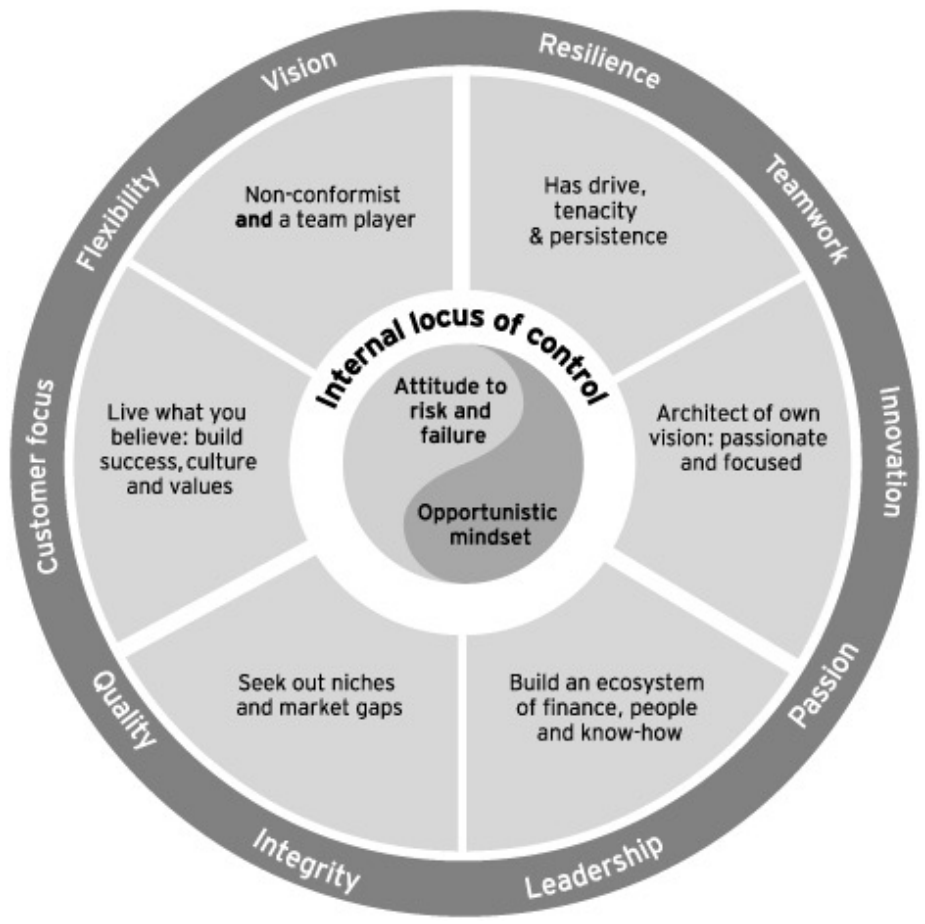

Figura 2. El DNA del empresario modelo.

Fuente: Ernst \& Young (2012) Nature or nurture? Decoding the DNA of the Entrepreneur. 
De acuerdo con Díaz (2014), los emprendimientos de alto impacto se identifican principalmente por los siguientes rasgos compartidos:

Colaboración. Generalmente se trata de colectivos multidisciplinarios de varios emprendedores que comparten pasiones y unen esfuerzos y conocimientos para alcanzar objetivos comunes.

Pasión. Cuentan con equipos apasionados en los que las habilidades y conocimientos de cada miembro del equipo se complementan para desarrollar proyectos mucho más interesantes y complejos de los que cada uno podría llevar a cabo de manera individual.

Simplicidad. Su principal objetivo es solucionar problemas y satisfacer necesidades de la manera más efectiva posible, de manera que no crearán productos o servicios complejos sino por el contrario, sus propuestas serán simples.

Aprovechamiento dela tecnología. Este tipo de emprendimientos usan la tecnología para tratar de reducir costos, de incrementar beneficios y de romper barreras geográficas que les permitan llegar a nuevos mercados. Aprovechando la tecnología tratan de maximizar el impacto de sus negocios.

Potencial internacional. Debido al aprovechamiento de las nuevas tecnologías los emprendimientos de alto impacto tienen el potencial de trascender globalmente involucrando para su negocio a clientes, proveedores, aliados y socios en cualquier parte del mundo.

Rentabilidad. Los emprendimientos de alto impacto deben generar una rentabilidad económica, ya que es una condición sin la cual sería imposible que se mantenga en el mercado.

Sostenibilidad. Los emprendimientos de alto impacto están apostándole a desarrollar propuestas de valor que contribuyan positivamente con la conservación del medio ambiente ya que los actuales consumidores están dispuestos a rechazar los productos y marcas que pongan en riesgo el entorno ambiental.

Orientación a las tendencias. Los emprendimientos de alto impacto buscan dirigirse a mercados en crecimiento que se basan en tendencias sociales y tecnológicas que impactan el entorno.

- Innovación. Una cualidad de estos emprendimientos es que se arriesgarán a hacer las cosas de manera diferente, pero siempre teniendo como objetivo crear valor para el segmento de clientes que han elegido. La innovación se da no solo en el producto o servicio que provee el emprendedor de alto impacto, se puede llevar a cabo en cualquier parte del proceso productivo.

- Impacto social. Además de crear valor para sus clientes, este tipo de emprendedores se alían con otros para crecer mutuamente, generando empleo y creando nuevas oportunidades. Además, contribuyen a la solución efectiva de problemáticas presentes en su entorno.

- Creación de valor. Un modelo de negocios crea valor cuando sus productos y servicios se convierten en algo importante para el consumidor. Los emprendimientos de alto impacto no solo venden productos o servicios, venden emociones, experiencias, sentimientos, beneficios, soluciones y valores.

Integrando las aportaciones de Ernst \& Young (2011) y Díaz (2014), es posible identificar un conjunto de atributos propios del emprendimiento y emprendedor de alto impacto: 
Rasgos del Emprendimiento de alto impacto

1. Colaboración

2. Multidisciplinariedad

3. Simplicidad

4. Rentabilidad

5. Aprovechamiento de tecnología

6. Potencial Internacional

7. Sostenibilidad

8. Innovación

9. Orientación a tendencias

10. Impacto Social

11. Creación de valor.

\section{Justificación, relevancia e impacto.}

Los emprendimientos de alto impacto, a diferencia de los emprendimientos de subsistencia o autoempleo, por sus características orientadas a la sostenibilidad económica, ambiental y social, así como por el enfoque global y de innovación, demandan sin duda de una cultura organizacional que permita favorecer las condiciones para cambiar el paradigma empresarial, de la supervivencia al alto impacto. En el Valle del Mezquital, dadas condiciones que han motivado la generación de las MiPyMEs y su financiamiento basado en remesas, es fundamental reorientar el desarrollo de nuevos emprendimientos para crear un nuevo tipo de empresas en la región: empresas que no solo logren permanecer en el tiempo y generar riqueza para su entorno, sino hacerlo de manera sostenible, creando valor para sus clientes, proveedores y comunidad, preservando el medio ambiente e impactando favorablemente en el desarrollo social de la región.

\section{Rasgos del emprendedor de alto impacto}

1. Visión

2. Pasión

3. Actitud

4. Formación

5. Resiliencia

6. Liderazgo

7. Experiencia

8. Conocimientos previos

9. Autocontrol

10. Apoyo de mentores

11. Apoyo familiar

Por ello, la relevancia de la presente propuesta se sustenta en la caracterización de los rasgos de la cultura organizacional de las MiPyMEs del Valle del Mezquital, ya que permitirá identificar los elementos que contribuyen en mayor medida al desarrollo de estrategias para impulsar el emprendimiento de alto impacto. La divulgación de los resultados, permitirá a las MiPyMEs del Valle de Mezquital alinear su cultura organizacional para disponerla al desarrollo de emprendimientos de alto impacto, posibilitando así, condiciones para que las MiPyMEs de la región aspiren a mantenerse y crecer, impactando en el desarrollo económico y social del Valle del Mezquital de manera sostenible. 


\section{Metodología y alcances}

La razón fundamental que ha motivado el presente estudio sobre la identificación de los rasgos de la cultura organizacional de las $\mathrm{Mi}$ PyMEs del Valle del Mezquital para impulsar el emprendimiento de alto impacto ha sido porque hasta el momento ninguna instancia pública o privada ha realizado algún estudio al respecto, y principalmente porque las actividades económicas sobre las que se sustenta el ingreso de las muchas familias en esta región del Estado de Hidalgo están relacionadas con la sobrevivencia, desarrollo y consolidación de las MiPyMEs. Para llevar a cabo la investigación propuesta fue preciso contar con una serie de elementos metodológicos que incluyeron: la definición del tipo de estudio, los participantes y los instrumentos de recopilación y de análisis de datos, todo ello basado en la utilización del modelo Competing Value Framework (Cameron y Quinn, 1999) para identificar el tipo de cultura dominante. El alcance de la investigación incluyó a una muestra validada de 80 MiPyMEs ubicadas en los municipios que conforman el Valle del Mezquital, mismos que comparten la problemática antes descrita.

\section{Tipo de estudio, diseño de la investigación y participantes.}

Dado que el estudio buscó identificar propiedades o características de un grupo de empresas a través de un análisis especifico y en virtud de que el tipo de información que se pretende recopilar acerca de las variables elegidas se realizará de forma independiente (Hernández, 2006), el estudio fue de tipo descriptivo. Puede catalogarse el presente estudio con un diseño de investigación no experimental dado a que se observaron las variables tal como se dan en su contexto natural para posteriormente efectuar un análisis sobre ellas, de manera que ninguna de las variables fue modificada durante el estudio. El estudio se realizó en un periodo de tiempo único para ser concluido en el año 2015. Se eligió un tamaño de muestra de 80 MiPyMES con registro en el Sistema de Administración Tributaria establecidas en alguno de los municipios que conforman la región del Valle del Mezquital en el Estado de Hidalgo.

\section{Modelo de diagnóstico e identificación de cultura dominante}

Para comenzar el estudio, se realizó un análisis de tres diferentes modelos de diagnóstico de la cultura organizacional que incluyen variables relacionadas con la implementación de estrategias de mejora de la calidad en la organización, como el modelo de Martínez y Robles (2009) que destaca la importancia del entendimiento y la satisfacción de los requisitos de los clientes internos y externos; el modelo de Buenaventura (1995) que se enfoca en el establecimiento de estrategias de motivación del personal para favorecer el cambio cultural que supone la implementación de estrategias de mejora; y el modelo de Hernández, et al (2007) quienes resaltan la importancia del desarrollo una cultura de calidad en la que existan individuos comprometidos y colaborativos, responsables de la satisfacción de sus clientes.

Posteriormente, se realizó una adaptación que integró, además de los modelos anteriores, las aportaciones de: Maull, Brown y Cliffe (2001) así como de: Robbins y Judge (2009) con lo cual se aseguraría que el modelo se oriente a posibilitar la implementación de estrategias de mejora de la calidad y el desempeño, aprovechando para ello los rasgos más relevantes de la cultura organizacional de las MiPyMEs. 
A este conjunto de variables, se incorporaron seis variables mas, extraídas del modelo Competing Value Framework (Cameron y Quinn, 1999) con la finalidad de identificar el tipo de cultura organizacional en este marco referencial y poder contrastar con los rasgos culturales de la primera parte del modelo de diagnóstico.

\section{Instrumentos}

Para llevar a cabo la recopilación de información se diseñaron cuatro instrumentos: una Ficha de identificación y cuestionario para recopilar, mediante un análisis cualitativo y cuantitativo, el perfil general de las organizaciones evaluadas así como el perfil de la organización hacia el emprendimiento de alto impacto; un cuestionario para identificar el perfil particular del emprendedor de alto impacto; un cuestionario para recopilar los datos cuantitativos del primer conjunto de variables orientado a ubicar los rasgos generales de la cultura de las organizaciones evaluadas; y finalmente un cuestionario destinado a recopilar los datos para la identificación del tipo de cultura dominante de acuerdo con el modelo Competing Value Framework de Cameron y Quinn (1999), realizando un análisis cuantitativo.

Tabla 2:

Instrumentos para el diagnóstico de la cultura organizacional en las MiPyMEs para impulsar el emprendimiento de alto impacto en el Valle del Mezquital

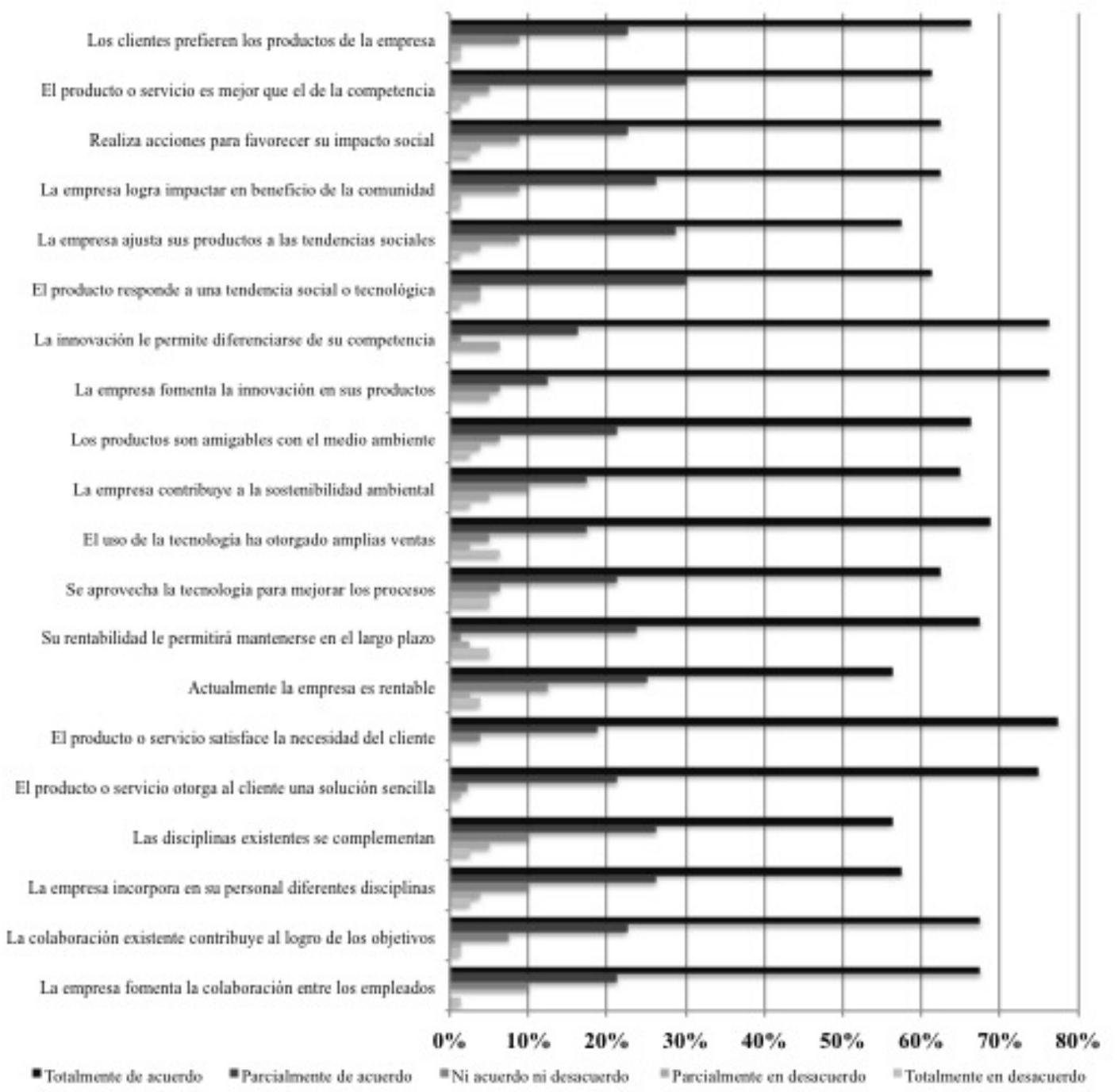


Tabla 2: (Continuación)

Instrumentos para el diagnóstico de la cultura organizacional en las MiPyMEs para impulsar el emprendimiento de alto impacto en el Valle del Mezquital

Los clientes prefieren las prodactos de la empresa

El producto o servicio es mejor que el de la competeneia

Realiza acciones para favorecer su impacto social

La empresa logra impactar en beneficio de la comunidad

La empresa ajusta sus productos a las tendencias sociales

El prodacto respoode a una tendencia social o tecnológicz

La innovación le permite diferenciarse de su competenciz

La empresa fomenta la innovación en sus prodactos

Los productos son amigables con el medio ambiente

La empresa coetribuye a la sostenibilidad ambiental

Eil uso de la tecnologia ha otorgado amplias ventas

Se aprovecha la tecnologia para mejorar los procesos

Su rentabilidad le permitira mantenerse en el largo plazo

Actualmente la empresa es rentable

El producto o servicio satisface la necesidad del clienie

El producto o servicio otorga al clienke una solución sencilla

Las disciplinas existentes se complementan

La empresa incorpora en sa personal diferentes disciplinas

La colaboración existente contribuye al logro de los objetivos

La empresa formenta la colaboración entre los empleados

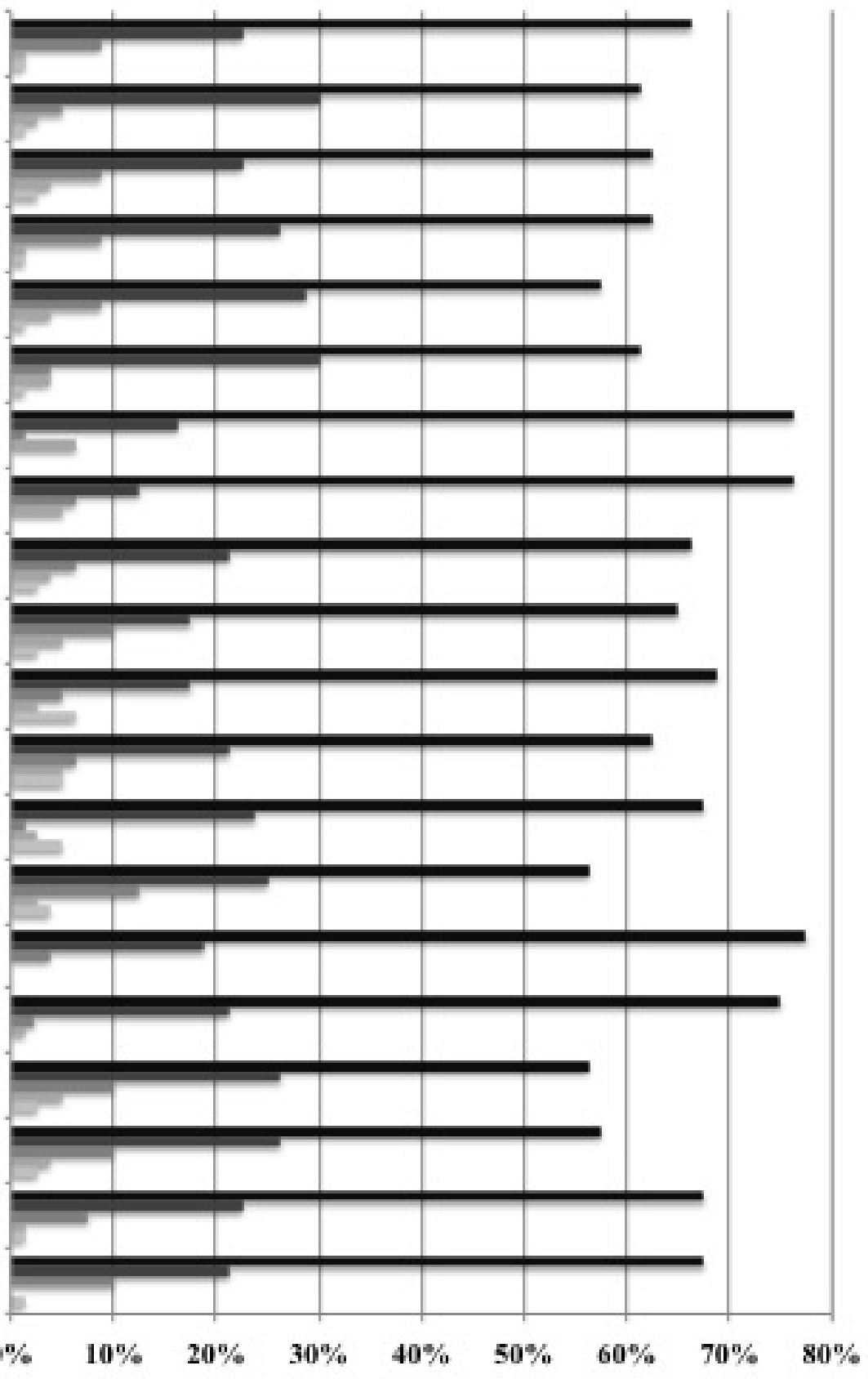

- Totalmente de acuerdo marcialmente de acuerdo

"Ni acuerdo ni desacoerdo

" Parcialmente en desacucrdo

"Totalmente en desacuendo

Nota. Fuente: Basado en Cameron, K. y Quinn, R. (1999). Diagnosing and Changing Organizational Culture. Addison-Wesley Series. New York.; en Ernst \& Young (2012) Nature or nurture? Decoding the DNA of the Entrepreneur y en Díaz (2014) Diez características de los emprendimientos de alto impacto. 
A continuación se describen los resultados del estudio agrupados por categorías del modelo utilizado:

\section{Perfil de las organizaciones.}

De acuerdo a la clasificación del INEGI (2010) el giro al que pertenecen las empresas que integraron la muestra es variado: el $60 \%$ es del giro de servicios, seguidas por el $27.5 \%$ que son del giro industrial y un $12.5 \%$ del giro comercial. El total de las empresas familiares se ubican en la región del Valle del Mezquital, en los municipios de Actopan, Alfajayucan, Atitalaquia, Cardonal, Chilcuautla, Francisco I. Madero, Ixmiquilpan, Mixquiahuala, Progreso de Obregón, San Salvador, Tasquillo, Tezontepec de Aldama, Tlahuelilpan y Tula de Allende.

En cuanto a su personalidad jurídica, el 55\% son personas físicas y el $45 \%$ son personas morales. En cuanto a las fuentes de los recursos para iniciar o fortalecer sus operaciones, se identificó que el $75 \%$ de las empresas realizan sus operaciones con recursos propios, el $17.5 \%$ con apoyo de financiamiento público y el $7.5 \%$ con financiamiento mixto. Respecto de su antigüedad, se identificó que el $12.5 \%$ de la organizaciones que integraron la muestra tienen menos de 5 años, el $43.75 \%$ entre 5 y 10 años, el $15 \%$ entre 10 y 20 años, el $20 \%$ entre 20 y 30 años; y el $8.75 \%$ tiene más de 30 años. El promedio de empleados por empresa fue de 18 colaboradores y el promedio de empleados familiares de los propietarios laborando en la organización fue de 3 . Se identificó que el $72.5 \%$ de las organizaciones cuentan con una misión declarada y el $75 \%$ de cuenta con una visión establecida. Del total de la muestra evaluada, el $78.75 \%$ cuenta con un conjunto de valores definidos. En el tema de proyección internacional, se identificó que el $17.5 \%$ del total de la muestra evaluada son MiPyMEs que exportan sus productos a otros países y que el $76.25 \%$ considera ampliar su mercado de manera global.
Los principales factores que favorecen el desempeño de las MiPyMEs evaluadas incluyen: la confianza del cliente, la calidad, la competitividad, el prestigio de las empresas, la atención al cliente, los precios, la ubicación, la innovación, el uso de tecnología, el equipo de trabajo, la disponibilidad de insumos, la mercadotecnia, la demanda de los productos y servicios, la buena administración, así como la capacitación y el compromiso de los colaboradores. En cuento a los factores que limitan el buen desempeño de las MiPyMEs, estos incluyen: la deficiencia financiera, la competencia desleal, rotación del personal, altos costos de producción, inseguridad, transporte deficiente, el tipo de cambio, la falta de regulación, la desorganización al interior de las empresas y la falta de perseverancia de los inversionistas.

\section{Perfil de la organización hacia el emprendimiento de allo impacto.}

El análisis del perfil de la organización para el emprendimiento de alto impacto realizado con base en la propuesta de Ernst \& Young (2012), consideró aspectos fundamentales para este tipo de emprendimientos tales como: colaboración, multidisciplinariedad, simplicidad, rentabilidad, aprovechamiento de tecnología, sostenibilidad, innovación, orientación a tendencias, impacto social y creación de valor.

En este sentido, la figura 2 permite apreciar que el principal rasgo que distingue a las organizaciones evaluadas es su orientación hacia la resolución de necesidades de sus clientes, posteriormente la innovación y la simplicidad constituyen atributos que perfilan a las organizaciones hacia el emprendimiento de alto impacto, seguidos por el uso de la tecnología y el fomento de la colaboración. Los aspectos que presentan menor fortaleza para que las organizaciones se orienten al 
emprendimiento de alto impacto son: la rentabilidad de las empresas y su orientación a la satisfacción de necesidades en el marco de nuevas tendencias sociales y tecnológicas.

De acuerdo con los resultados obtenidos, la multidisciplinariedad es una condición en la que las organizaciones aún no muestran fortaleza suficiente para orientarse al emprendimiento de alto impacto

Los clientes prefieren los prodoctos de la empresz

El producto o servicio es mejor que el de la competenciz

Realiza acciones para favorecer su impacto social

La empresa logra impactar en beneficio de la comunidad

La empresa jjusta sus productos a las tendencias sociales

El prodacto respoode a uns tendenxia social o tecnológica

La innoración le permite diferenciarse de su competencis

La empresa fomenta la imnovación en sus prodactos

Los productos son amigables son el medio ambiente

La empresa coetribugv a la sostenibilidad ambiental

El uno de la tectnologia ha otorzado amplias ventas

Se aprovecha la tectologia para mejorar los procesos

Su rentabilidad le permitiri mantenerse en el largo plazo

Actualmente la empresa es rentable

E producto o servicio satisface la necesidad del cliente

El producto o servicio otorga al cliente una solución sencilla

Las disciplinas existentes se complementan

La empresa incorpora en sa personal diferentes disciplinas

L.a colaboración existente contribuye al logro de las objetivos

La empresa fomenta la colaboración entre los empleados

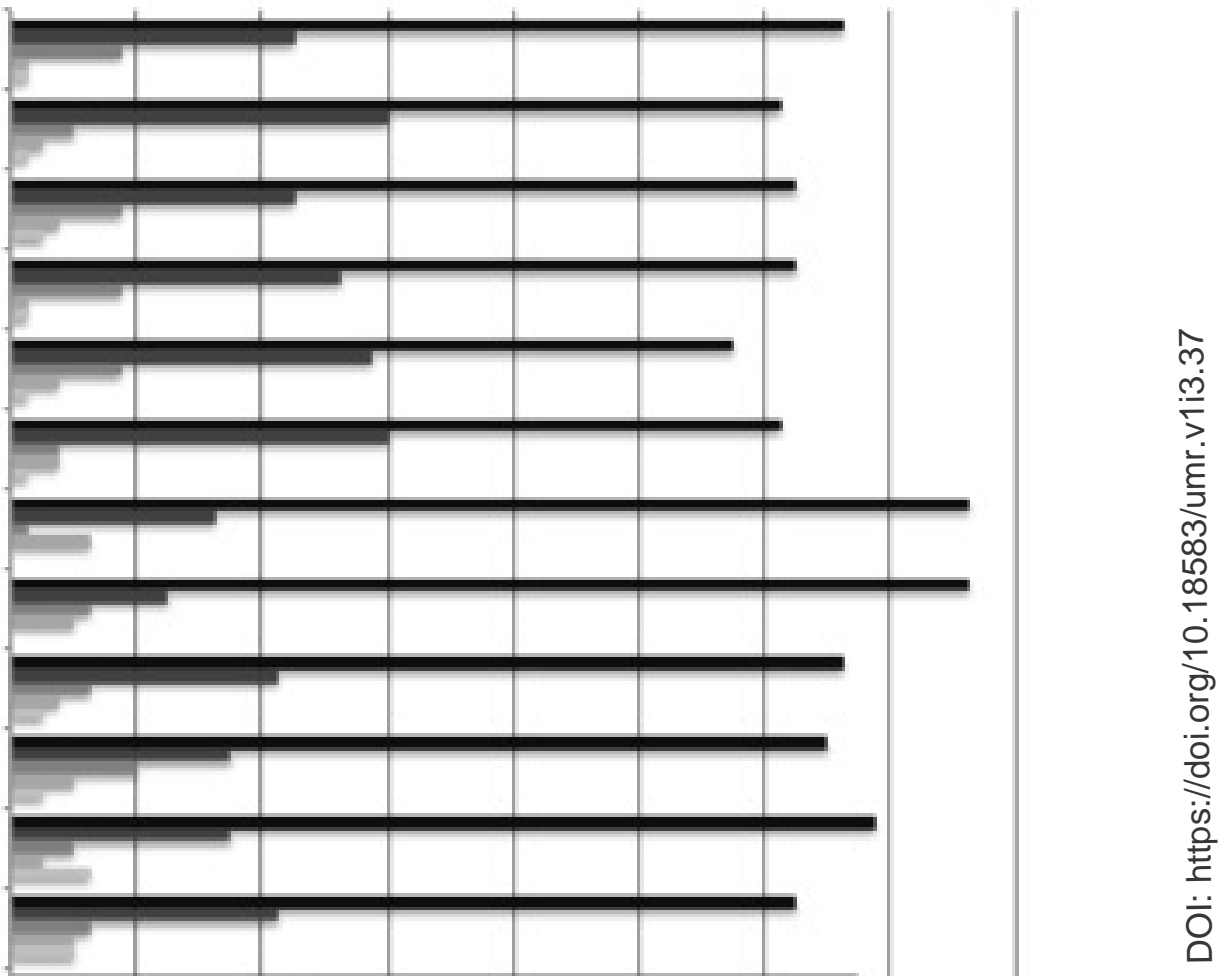

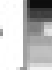
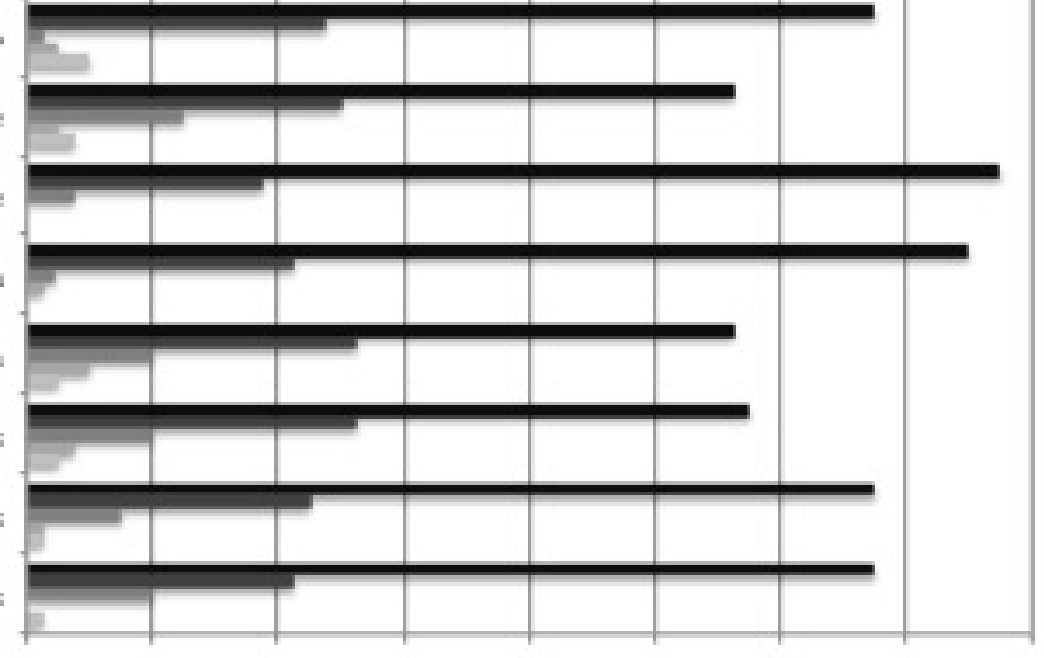

$\begin{array}{lllllllll}0 \% & 10 \% & 20 \% & 30 \% & 40 \% & 50 \% & 60 \% & 70 \% & 80 \%\end{array}$

"Ni acuerdo ni desacoordo "Parcialmente en desacucrdo "Totalmente en desacuerdo

- Totalmente de acuerdo "Parcialmente de acuerdo

Figura 3. Resultados del Perfil de la organización hacia el emprendimiento de alto impacto. 


\section{Perfil de emprendedor de alto impacto.}

El conjunto de características y atributos asociados a los emprendedores de alto impacto que fueron analizados en esta categoría incluyó aspectos como: visión personal, pasión por la idea o el emprendimiento, actitud, resiliencia, formación, liderazgo, experiencia previa, manejo del autocontrol, así como la existencia de apoyo de mentores y apoyo familiar para la implementación del emprendimiento.

Los clienies preficten los prodactos de la enceresa

El producto o servicio es mejor que el de la competencia

Realiza acciones para favorecer su impacto social

La empresa logra impactar en beneficio de la comunidad

La empresa ajusta sus productos a las tendencias sociales

El prodacto respoode a una tendencia social o tecnológica

La innovación le permite diferenciarse de su competencia

La empresa fomenta la innovación en sus prodactos

Los productos son amigables con el medio ambiente

La empresa coetribure a la soostenibilidad ambiental

El teoo de la tecnologia ha oforgado amplias ventas

Se aprovecha la tecrologia para mejorar los procesos

Su rentabilidad le permitirá mantenerse en el largo plazo

Actualmente la empresa es rentable

El producto o servicio satisface la necesidad del cliente

El producto o servicio otorga al clicnoc una solución sencilla

Las disciplinas existentes se complementan

La empresa incorpora en sa personal diferentes disciplinas

La colaboracion existenle contribuye al logro de las objetivos

La cmpresa fomonta la colaboración entre los empleados
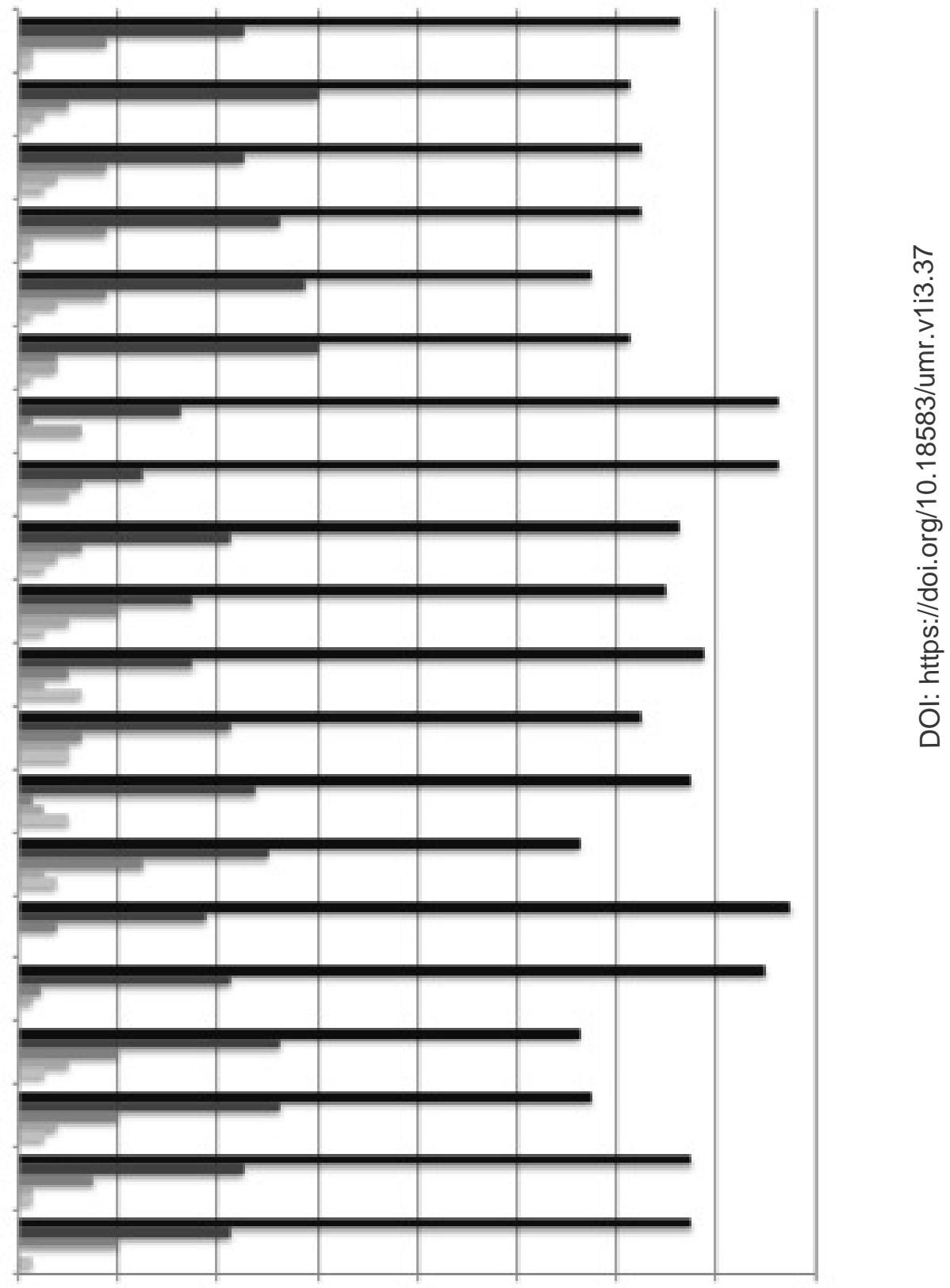

$\begin{array}{lllllllll}0 \% & 10 \% & 20 \% & 30 \% & 40 \% & 50 \% & 60 \% & 70 \% & 80 \%\end{array}$

- Totalmente de acuerdo

- Parcialmente de acuerdo

" Ni acuerdo mi desacuerdo

"Parcialmente en desacuerdo

- Totalmente en desacuerdo

Figura 4. Resultados del Perfil emprendedor de alto impacto 
En esta categoría es posible identificar hallazgos de mucha relevancia para reconocer el perfil del emprendedor como un perfil orientado al emprendimiento de alto impacto, tal es el caso de las variables con mayor fortaleza encontradas: el deseo personal del emprendedor por tener su propia empresa y la pasión que deposita en su emprendimiento o idea.

Le siguen en orden de frecuencia, el establecimiento de una visión personal y el énfasis en transmitir a los colaboradores de la pasión por el crecimiento del emprendimiento, seguidas por el reconocimiento de la importancia que para este tipo de emprendedores tienen la actitud, la resiliencia y el liderazgo.

Destaca también que la mayoría de los emprendedores reconocen el autocontrol como una condición clave para el crecimiento de su empresa y que en su mayoría están dispuestos a apoyar a algún familiar en su emprendimiento, no obstante que la mayoría no recibió este tipo de apoyo.

Respecto de los aspectos con mayor debilidad identificados en esta categoría, se encuentra la tolerancia al fracaso empresarial ya que es la variable que la mayoría de los emprendedores reconocen como carente de fortaleza y que es clave para adquirir un perfil de emprendedor de alto impacto.

La experiencia actual y previa; así como la formación profesional no son variables que denoten fortaleza en la muestra evaluada y que sin embargo han sido reconocidas por diversos autores como condiciones clave para favorecer el emprendimiento de alto impacto.

\section{Comunicación}

Para la evaluación de esta variable se consideró no solo la existencia de los medios utilizados para la comunicación, sino su efectividad, el tipo de mensajes utilizados, la claridad de la información, así como la apertura para la retroalimentación por parte de colaboradores y clientes En esta categoría, las mayores fortalezas de las organizaciones se encuentran tanto en el clima de apertura propicio para la comunicación, así como en el compromiso con el logro de los objetivos que refleja la comunicación interna, seguidas por la claridad de los mensajes por parte de la dirección y por la diversidad de medios existentes para la comunicación. Las variables que demuestran menor fortaleza son las relacionadas con la suficiencia de los mecanismos de retroalimentación para expresar las quejas y sugerencias por parte de los clientes, así como la efectividad y agilidad de los medios de comunicación existentes.

\section{Clima organizacional}

De acuerdo a la clasificación del INEGI (2010) el giro al que pertenecen las empresas que integraron la muestra es variado: el $60 \%$ es del giro de servicios, seguidas por el $27.5 \%$ que son del giro industrial y un $12.5 \%$ del giro comercial.

Destaca el reconocimiento del cuidado del medio ambiente, la conformidad con los salarios y prestaciones, así como con horarios y tiempos de descanso.

La percepción de las buenas relaciones entre compañeros de trabajo, la existencia de espacios físicos confortables, así como la disposición para el trabajo colaborativo, se inclinaron hacia la satisfacción

Sin embargo, se aprecian áreas de oportunidad en la mejora de aspectos tales como: las oportunidades de crecimiento y la existencia de medidas de racionalidad para lograr ahorros, ya que la percepción en estos aspectos fue de insatisfacción, lo cual puede afectar el clima de la organización. 
Existen mocanismos para expresar quejas y sugerencias de los clienks

Existe un ambiente de apertura para decir las cosas de fomma clara y directa

Las conversaciones cotidianas reflejan la convicción y sompromiso por el logro de los objetivos de la empresa

Los mencajes de las directivos reflejan, en forma clara, lo que quieren decir

Los medios de comunicación existentes son efectivos y igiles

Existen differentes medios para la comunicación organizacioeal

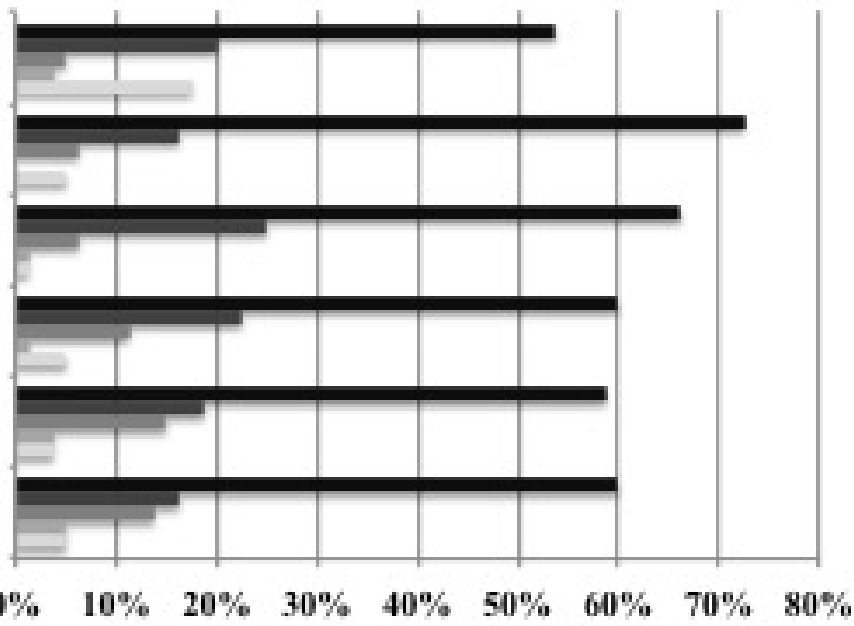

- Toeslmente de acuerdo - Parcialmente de acuerdo "Ni acourdo ni desacuerdo "Parcialmente en desacoxrdo "Totalmente en desacoxrdo

Figura 5. Resultados de la categoría: Comunicación

Las autoridades coentan con el respeto de los trabajadores

Las relaciones coen las autoridades son adecuadas para un trabajo productivo

Existe disposición para trabajar y aprender en equipo

Hay buenas relaciones entre compañeros de trabajo

La empresa actũa para el cuidado de la ecologia

Las medidas de racionalidad permiten ahorros

La calidad de vida en el trabajo es satisfactoria

Se cocntan coe espacios fisicos suficientes y conforiables para desarnollar el trabajo

Existen oportunidades de asexnso en la empresa

Los salarios $y$ prestaciones estin acordes al mercado

Los horarios y tiempos de descanso son adecusados

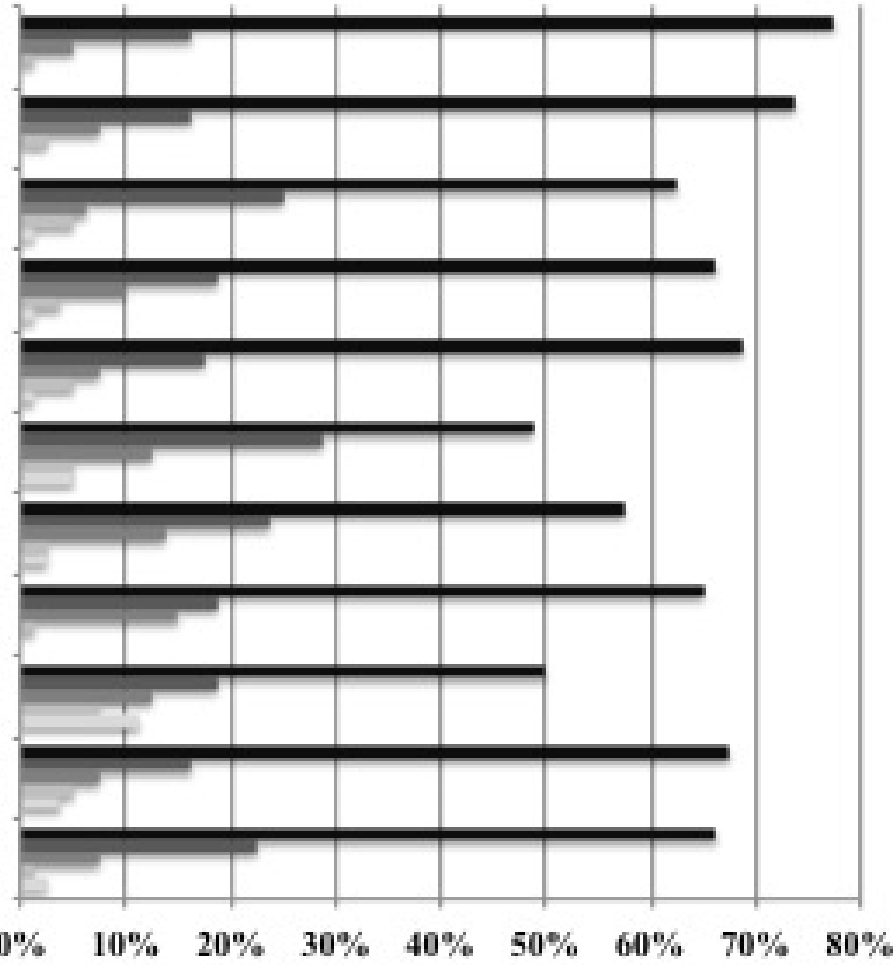

- Totalmente de acuerdo

- Parcialmente de acucrdo

- Ni acuendo ni desacuerdo

"Parcislmente en desacuendo

"Totalmente en desacuxrdo

Figura 6. Resultados de la categoría: Clima Organizacional 


\section{Símbolos y signos}

La evaluación respecto de los símbolos y signos como parte de la cultura organizacional, permite apreciar fortalezas de las MiPyMEs en cuanto a la difusión de una imagen institucional y la utilización de símbolos que la robustecen tales como el uniforme, logotipos y elementos mercadológicos. De igual manera, permite identificar el aprovechamiento de rituales y creencias a favor de los objetivos que persiguen las organizaciones.

En esta categoría, las organizaciones evaluadas demostraron debilidad en todas sus variables ya que menos del $50 \%$ indicaron que hay una permanente difusión de la organización, no obstante, la mayoría reconocen que las creencias sobre el trabajo en la empresa son compartidas y que estas reflejan la convicción en el cumplimiento de los objetivos.

En cuanto a la existencia de símbolos que fortalezcan la imagen de las organizaciones, tales como el uso de uniformes o insignias, la percepción es ligeramente de satisfacción ya que el $63 \%$ indican que se esta condición se promueve en la organización.

Fue posible identificar oportunidades para el logro de mayor cohesión tanto en la existencia de rituales que distinguen la vida de las organizaciones (tales como celebraciones o ceremonias), como en la compartición de dichos rituales entre los miembros de la organización, ya que la percepción identificada es la de mayor debilidad en esta categoría.

\section{Estillo directivo}

Las mayores fortalezas de las organizaciones evaluadas en la categoría de estilo directivo radican en el establecimiento de acuerdos para la resolución de conflictos y en la apertura que muestran los directivos para las propuestas de cambio y para la innovacion. Destaca igualmente la motivación que generan los directivos al personal a través de su propio ejemplo, la forma positiva en que se promueve la solución de diferencias, así como la percepción generalizada de que la asignación de responsabilidades se realiza de manera equitativa y respetuosa, todo lo anterior motivado por el estilo de dirección establecido.

Se ha identificado que las mayores áreas de oportunidad en cuanto el estilo directivo, se encuentran en la reacción ante los cambios en la empresa, en la puntualidad de la información respecto de dichos cambios, así como en el establecimiento y claridad de las expectativas que los directivos tienen respecto a sus colaboradores; no obstante, se aprecia que existe una percepción positiva de que los resultados que se han obtenido, son fruto del trabajo en equipo y que esta colaboración se promueve de manera permanente. 
Las steencias sobre el trabajo de la empresa son compartidas

Las creencias de los trabajadores reflejan la convicción por colaborar en el cumplimiento de los objetivas

Las rituaks soe compartidas por los mismbros de la empresa

Existen rituales (celebraciones, ceremonias, etc.) que distinguen la vida de la empress

Se promueve el uso de uniforme, insignias u otros simbolos para fortalecer la imsgen corporativa

Hay permanente difusión de la imagen corporativa de la empresa

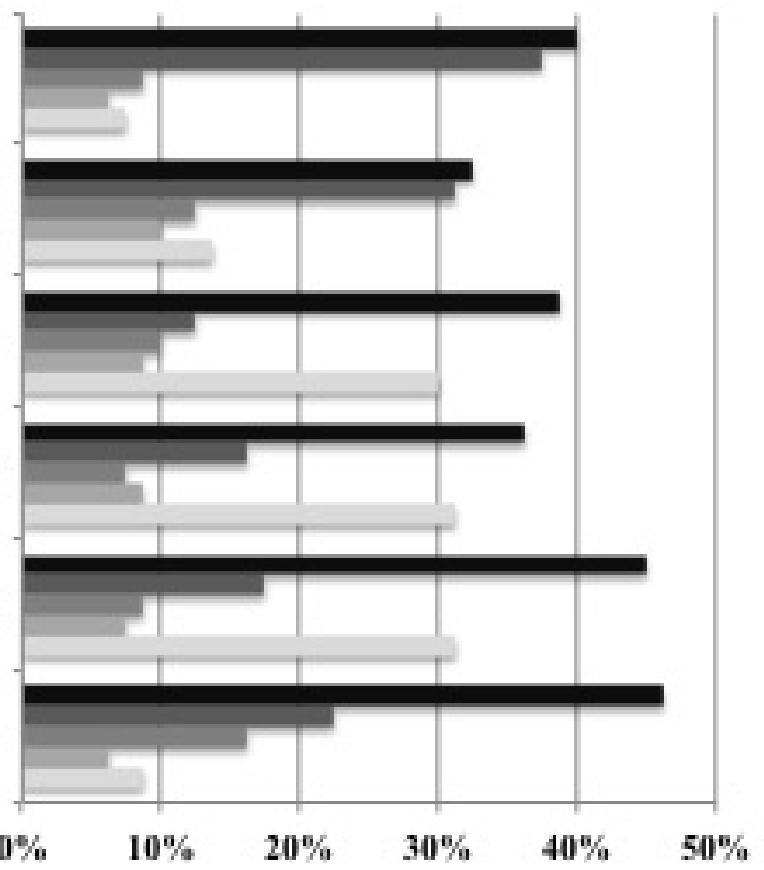

- Totalmente de acuendo "Parcialmente de acuerdo $=$ Ni acuendo ni desacuendo "Parcialmente en desacuerdo "Totalmente en desacuerdo

Figura 7. Resultados de la categoría: Símbolos y signos.

El acuerdo es la mejor forma para resolver los conflictos que se criginan en la empress

Cusndo existen diferencias entre el personal, siempre se actúa de forma positiva para resolver los conflictos

Los cambios en la empreas se asumen de forma positiva

Las cambios en la empresa se informan puntualmente

Los resultadas obtemidos son producto del trabujo en equipo

Se promueve de forma permanente el trabajo en equipo para el logro de las metas

Los directives estin abiertos al cambio y a la ineovación

Las directinos motivan el desempetio a tranvis del ejemplo

La asignakiče de responsabilidades se realiza de forma equitativa y respetiouss

Las directivos hacen saber, clara y explicitamente, lo que se espera de cada colaborador
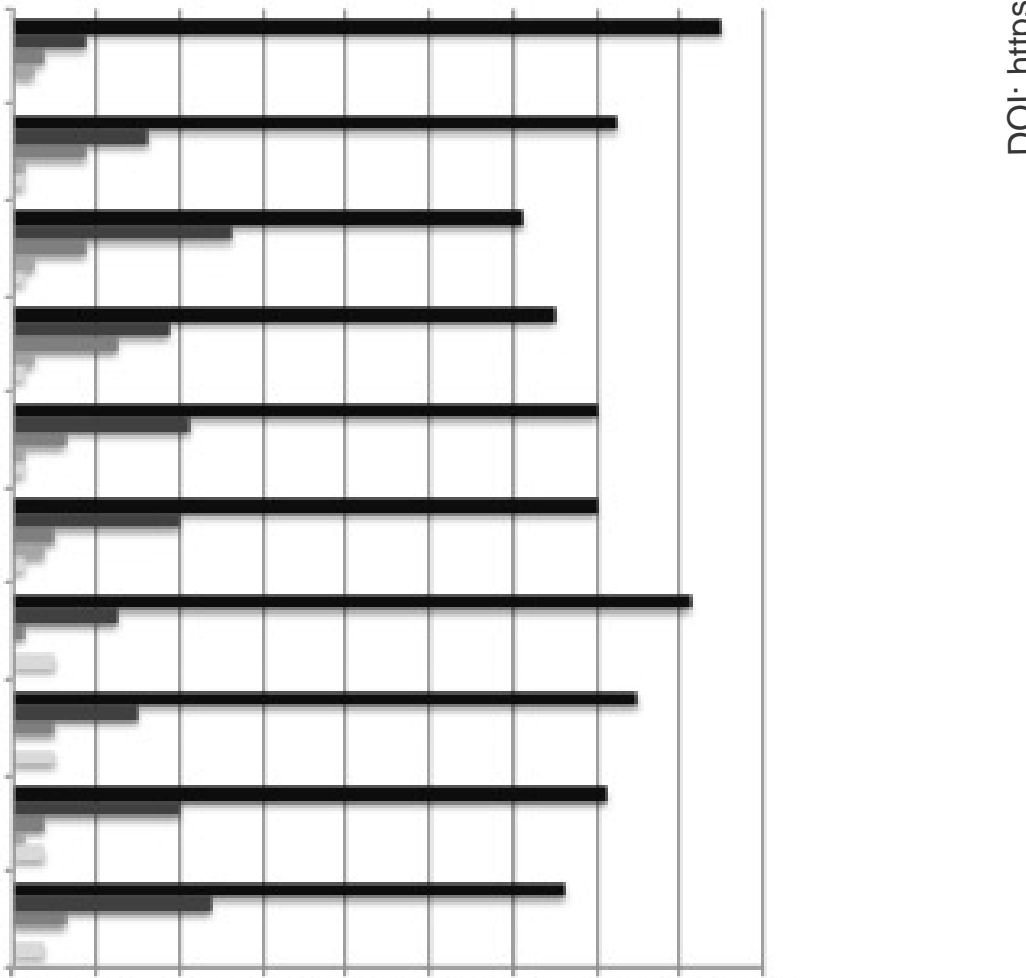

$\begin{array}{llllllllll}0 \% & 10 \% & 20 \% & 30 \% & 40 \% & 50 \% & 60 \% & 70 \% & 80 \% & 90 \%\end{array}$

- Totalmente de acuerdo "Parcialmente de acocrdo "Ni scuerdo ni desacuerdo "Parcialmente en desacuerdo "Totalmente en desacourdo

Figura 8. Resultados de la categoría: Estilo Directivo. 


\section{Motivación,reconocimiento y estímulos}

En esta categoría se evaluó la percepción de la organización respecto de las estrategias de reconocimiento establecidas para promover la motivación del personal, así como los estímulos y prestaciones económicas existentes, ya que son determinantes para una cultura organizacional orientada a la mejora continua del desempeño.

En este sentido, fue posible identificar que el área de mayor fortaleza la constituye la percepción de que existe una asignación equitativa de estímulos al desempeño. En la mayoría de los casos las empresas cuentan con prestaciones adicionales al sueldo y en la generalidad, los estímulos establecidos para reconocer el desempeño resultan motivantes para el personal.

Sin embargo, existen debilidades plenamente identificadas en cuanto a que menos del $50 \%$ de las empresas evaluadas efectúa los reconocimientos a sus colaboradores en forma pública, lo cual podría brindar al personal mejor percepción y visibilidad de las estrategias de reconocimiento.

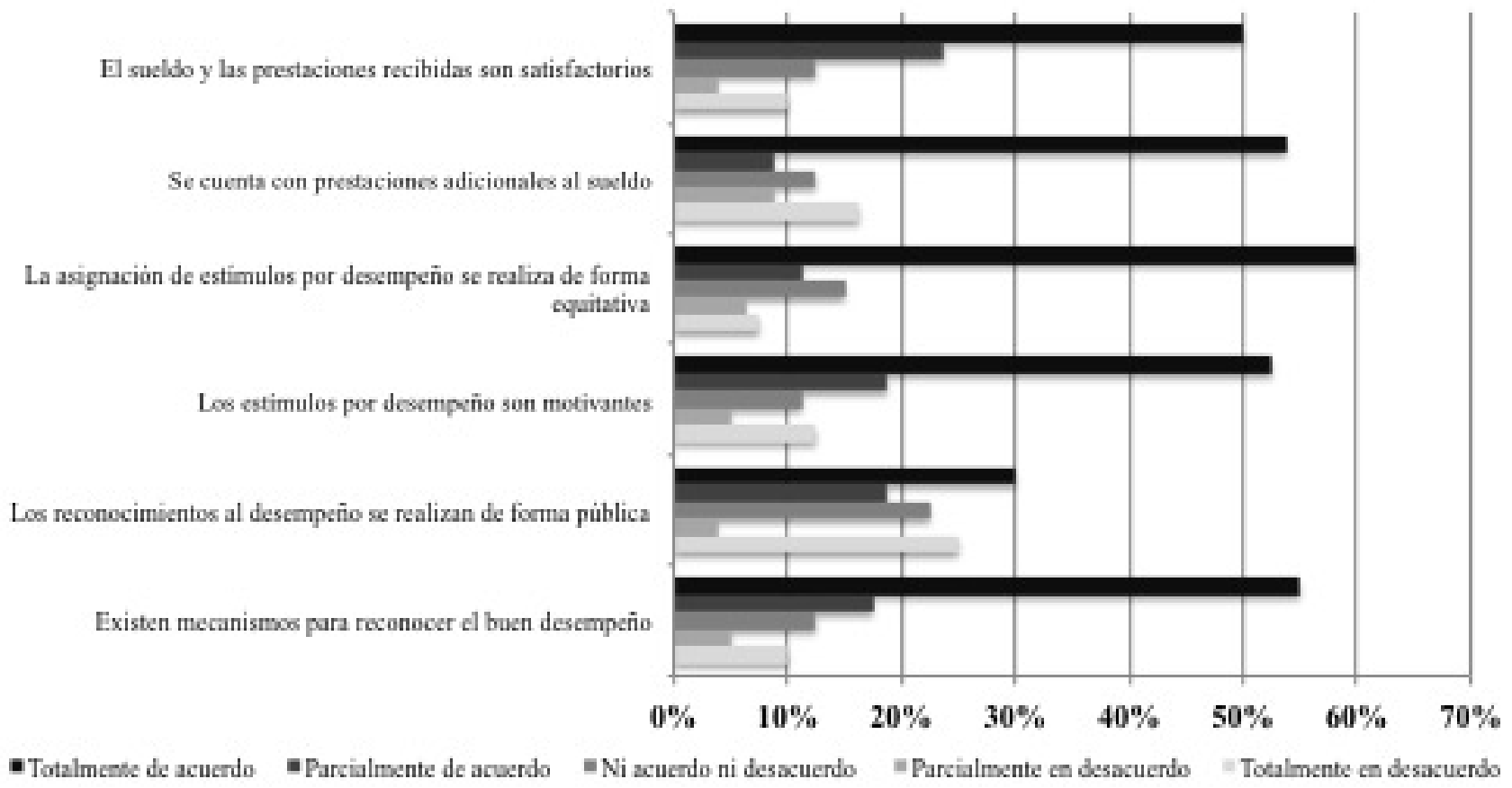

Figura 9. Resultados de la categoría: Motivación, reconocimiento y estímulos.

\section{Normatividad Interna}

Como resultado de la evaluación de la normatividad interna, fue posible identificar que en la mayoría de las empresas existe un reglamento interno que regula las actividades de la organización, no obstante que en un $20 \%$ no se cuenta con normativa, este mismo resultado se da en cuanto a la aplicación de la normatividad a todos los trabajadores.

En cuanto a la aplicación y difusión permanente de la normatividad interna, se aprecia que existen áreas de oportunidad claramente identificadas ya que más del $20 \%$ de empresas consideran que esta aplicación y difusión del reglamento interno, no se lleva a cabo. 
El reglamento interno de la cmpresa se aplica para todos los trabajadores

Fil reglanento interno de la empresa se aplica de forma permanente

El reglamento interno de la empresa se difunde de forma permanente

Existe un reglamento interno para regular las actividades de los trabajadores en la empresa

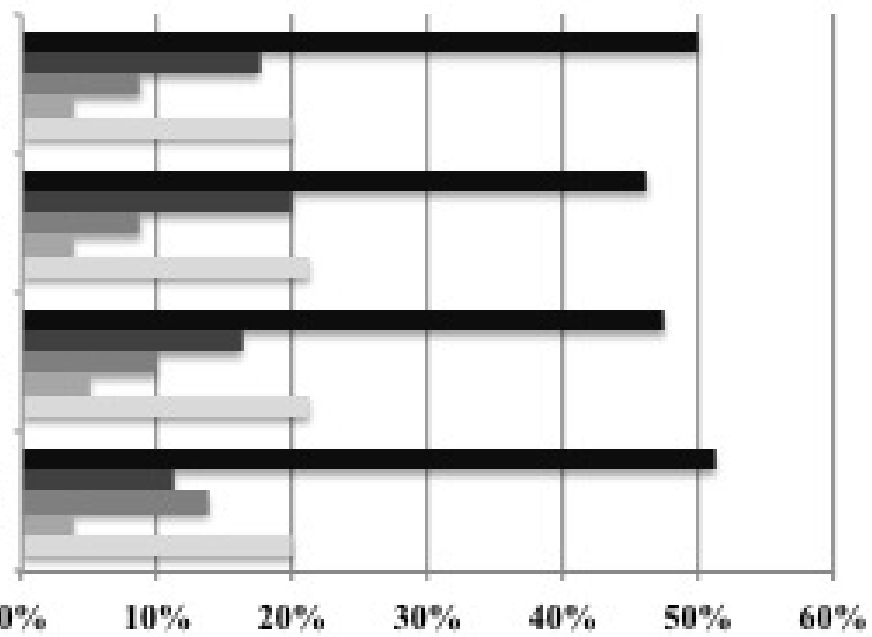

- Totalmente de acuerdo

- Parcialmente de acuerdo

"Ni acoerdo ni desacucrdo

" Parcialmente en desacuendo

Totalmente en desacuerdo

Figura 10. Resultados de la categoría: Motivación, reconocimiento y estímulos.

\section{Capacitación y desarrollo}

En muchas de las organizaciones evaluadas existen estrategias de capacitación para todo o parte del personal (68\%), las cuales se llevan a cabo de forma equitativa en su mayoría. Esta condición permite que exista una percepción ligeramente favorable de que se promueve el desarrollo profesional de manera permanente. Sin embargo, la inexistencia de planes de desarrollo profesional para cada colaborador de la empresa constituye el área de mayor debilidad en esta categoría.

Se promoeve el desarrollo profesional de forma permanente

Existe un plan de desarrollo profesional para cada colaborador en la empress

Los programas de capacitación se implementan de forma equitativa

Existen programas de capacitacióe para todo el persoesal

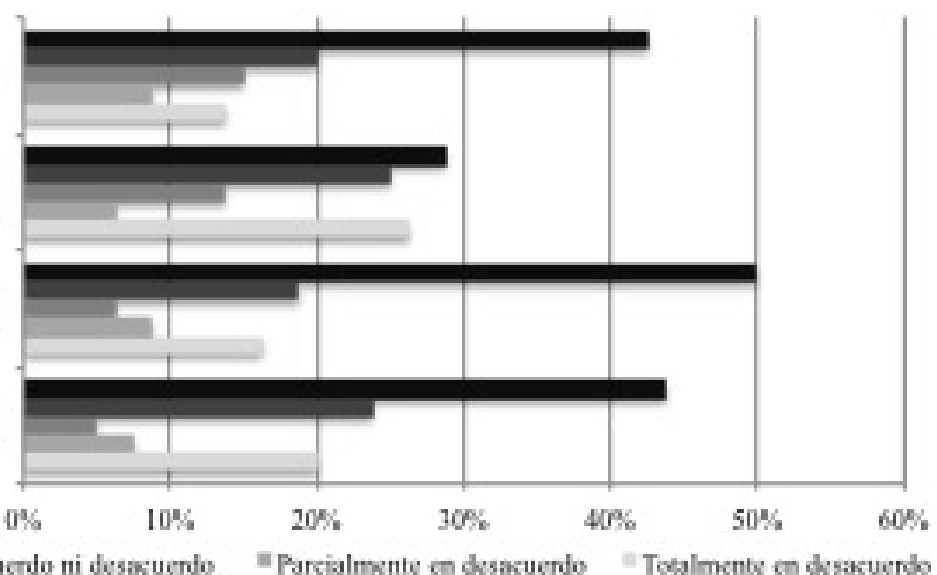

- Totalmente de acuerdo

"Parcialmonte de acoordo

" $\mathrm{Ni}$ scuerdo ni desacuerdo

"Parcialmonte en desacuendo

Totalmente en desacuerdo

Figura 11. Resultados de la categoría: Capacitación y desarrollo. 


\section{Visión empresarial}

Existe la percepción en la mayoría de las organizaciones que se tienen definidas las metas en el corto y mediano plazo, y que las actividades que se desarrollan se orientan al cumplimiento de dichas metas, sin embargo, se aprecia que no necesariamente cuentan con planes de trabajo para describir la manera en que alcanzarán sus objetivos, ni realizan autoevaluaciones para determinar sus fortalezas y debilidades.

En la empresa se establecen planes de mejoramiento

En la empresa se realizan autoevaluacioess para determinar las fortalezas y debrilidades

La empresa tiene definidos mocanismos para monitorear el cumplimiento de las metas establecidas

Las actividades que se ralizan estain enfocadas al cumplimiento de metas

En la empresa se cuenta con un plan de trabajo para las metas qoe se quieren lograr

La empresa ticne una definición clara de lo que quicte lograr en el corto $y$ mediano plaso

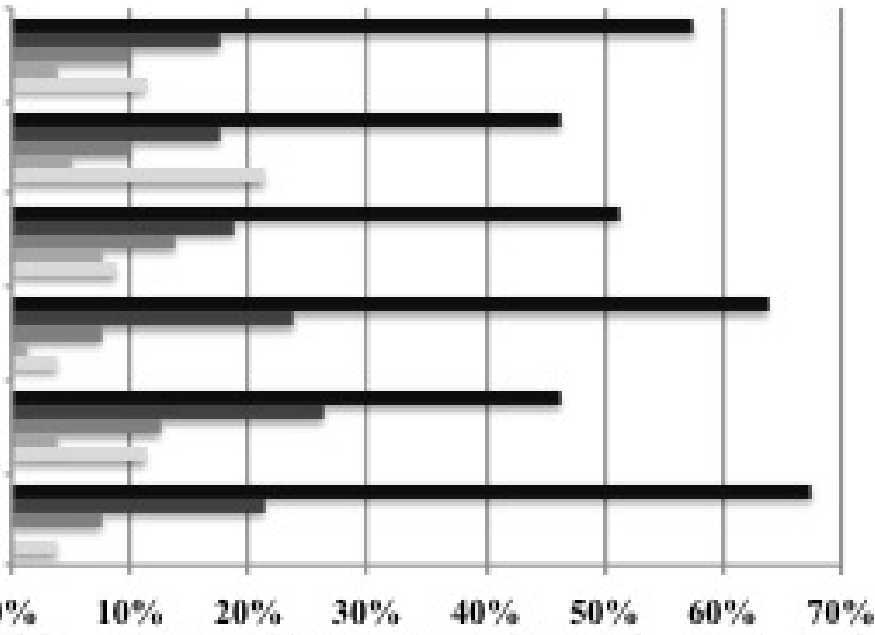

- Totalmente de acuendo

- Parcialmente de acwerdo

- Ni zcuendo ni desacuendo

" Parcialmente en desacuendo

"Totalmente en desacuerdo

Figura 12. Resultados de la categoría: Visión empresarial.

\section{Capacidad de Gestión}

En esta categoría se identificó que la mayor fortaleza de las organizaciones de la muestra radica en contar con los insumos necesarios para el desarrollo adecuado de las actividades, así como en la mejora continua de su equipamiento e instalaciones, no obstante que la incorporación de tecnología para la mejora de la calidad no ha sido suficientemente atendida y que se demandan procedimientos que permitan estandarizar las actividades. El área de mayor debilidad en esta categoría la constituye la inexistencia de programas de mejora de la calidad.

Se coenta coe la documentación de procedimientos para facilitar el trabajo en la empresa

Existe un programa de calidad en la empress

La empresa cuenta con la tecnologia adecuada para competir en el mercado

Se incorpora tecnologia en la empresa para la mejora de la calidad

La empresa realiza mejoras continuas en sas equipos e instalaciones

Se cuenta con los insumos necesarios para realizar el trabajo en tiempo y forma

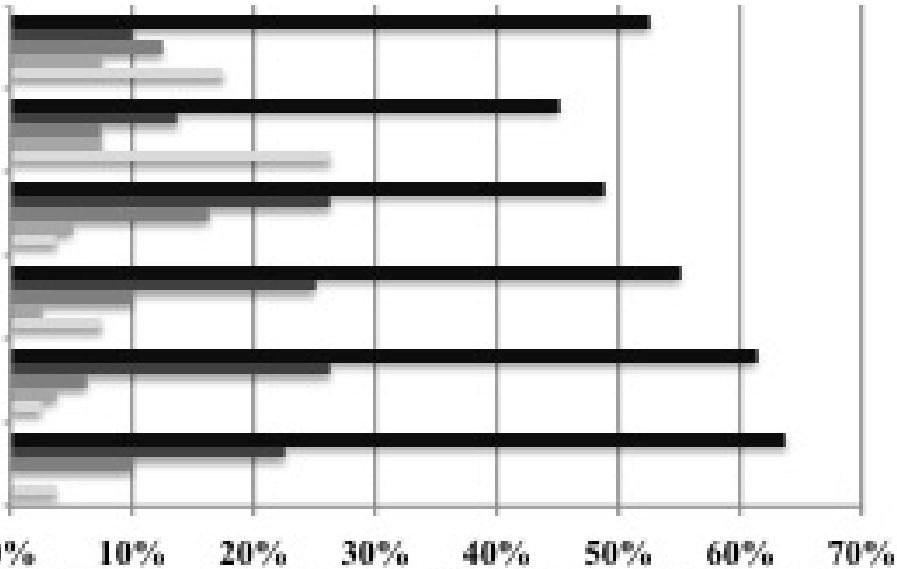

"Ni acoordo ni desacucrdo "Parcialmente en desacuerdo "Totalmente en desacuendo

- Totalmente de acourdo

- Parcialmente de acoxrdo

Figura 13. Resultados de la categoría: Visión empresarial. 


\section{Características dominantes}

Tomando en consideración el modelo de Cameron y Quinn (1999), en esta sección de resultados fue posible identificar que en las organizaciones evaluadas predomina en primer lugar las características relacionadas con la Cultura Mercado (29\%), seguidas por la Cultura Jerarquizada (27\%). En el primer caso, la organización está muy orientada a los resultados y la mayor preocupación es hacer el trabajo bien hecho. En este tipo de organizaciones las personas son competitivas entre sí. En el segundo caso la organización es muy estructurada y controlada, son organizaciones donde generalmente los procedimientos dicen a las personas qué hacer.

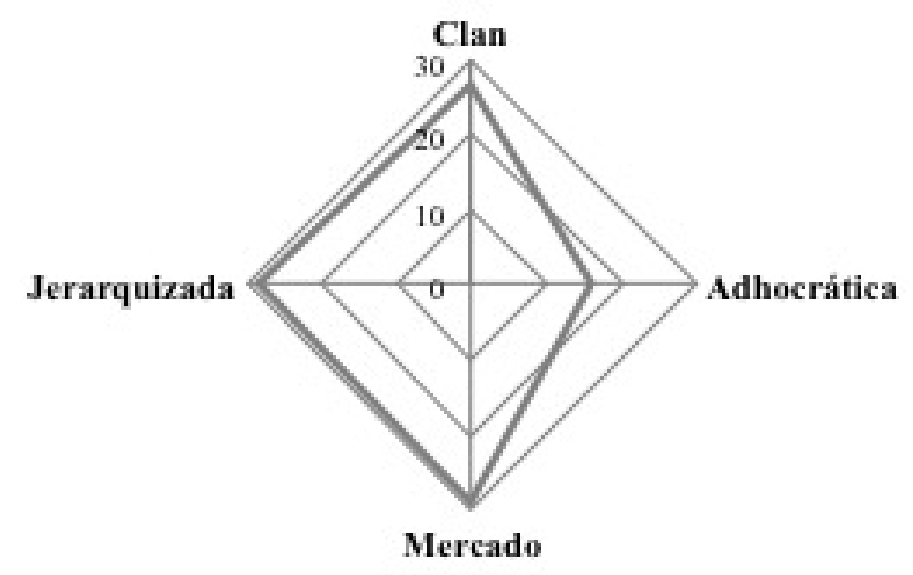

Figura 14. Resultados de la categoría: Características Dominantes.

\section{Líderes de la organización}

Esta categoría de evaluación considera la orientación del liderazgo hacia los propósitos que identifican a cada uno de los tipos de cultura organizacional que proponen Cameron y Quinn (1999). En este sentido, fue posible identificar que los tipos de cultura preponderante son: Jerarquizada (29\%), seguida por Clan (26\%) y Mercado (25\%). Esto significa que en la mayor parte de organizaciones el- liderazgo es generalmente usado para coordinar, organizar o mejorar la eficiencia, pero también como un instrumento para facilitar, guiar y enseñar a sus miembros; así como para el asegurar los resultados.

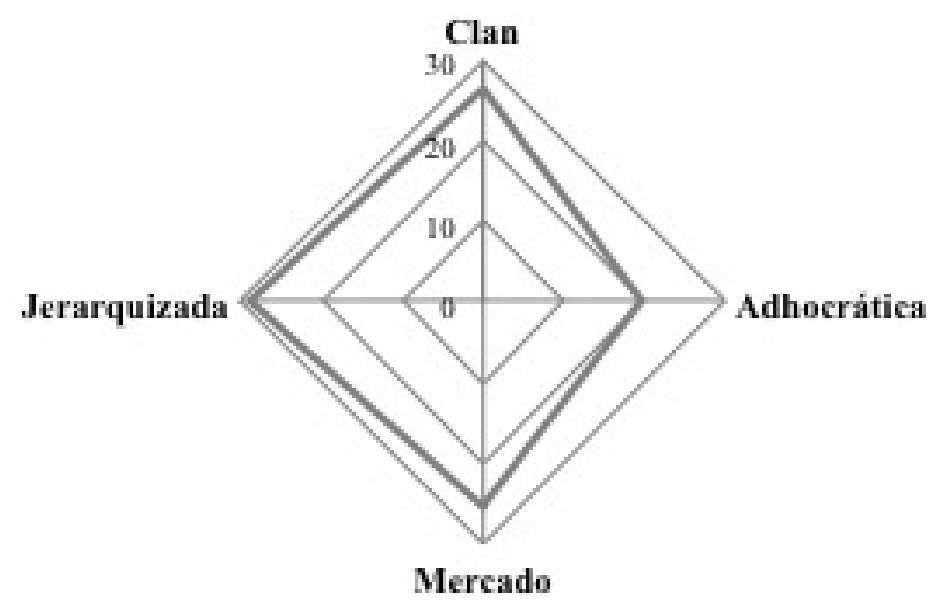

Figura 15. Resultados de la categoría: Líderes de la organización.

\section{Estilo Gerencial}

La categoría de estilo gerencial considera características específicas determinar el estilo de manejo del recurso humano en las organizaciones. En este sentido, fue posible identificar que la percepción del estilo gerencial se orienta principalmente hacia la cultura Jerarquizada (31\%) y a la cultura Clan en segundo lugar (29\%). En este caso en la mayoría de organizaciones el estilo de manejo del recurso humano se caracteriza por dar seguridad de los puestos de trabajo y la estabilidad en las relaciones humanas, así como por el trabajo en equipo, el consenso y la participación. 


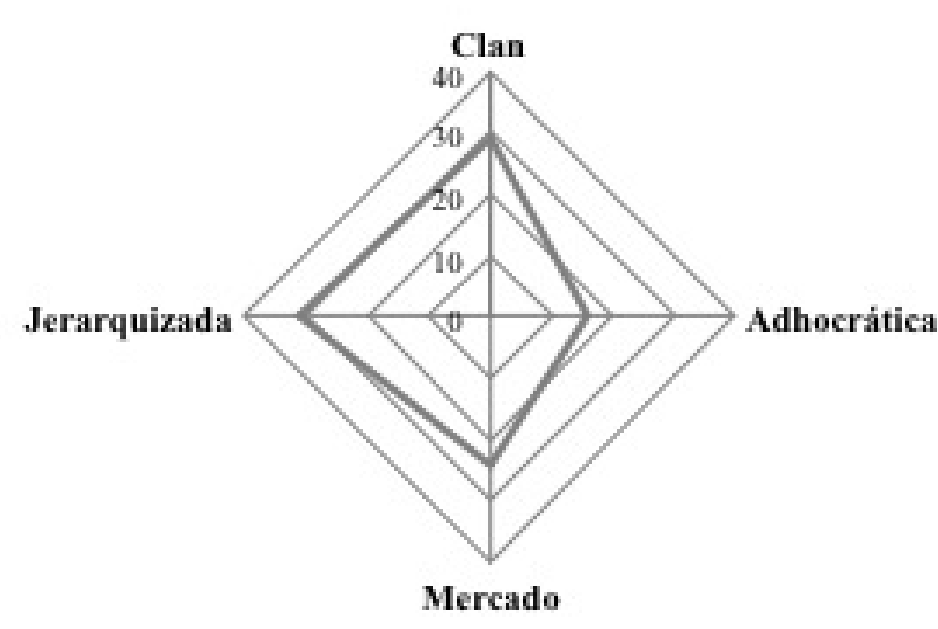

Figura 16. Resultados de la categoría: Líderes de la organización.

\section{Unión de la organización}

Respecto de la categoría de Unión de la organización, los resultados muestran una mayor orientación hacia la cultura Clan (30\%) en primer término y hacia la cultura jerarquizada en segundo lugar (25\%). Esto significa que lo que mantiene unido a la mayoría de las organizaciones es la lealtad y la confianza mutua, así como las políticas y las reglas establecidas para mantener a la organización en marcha.

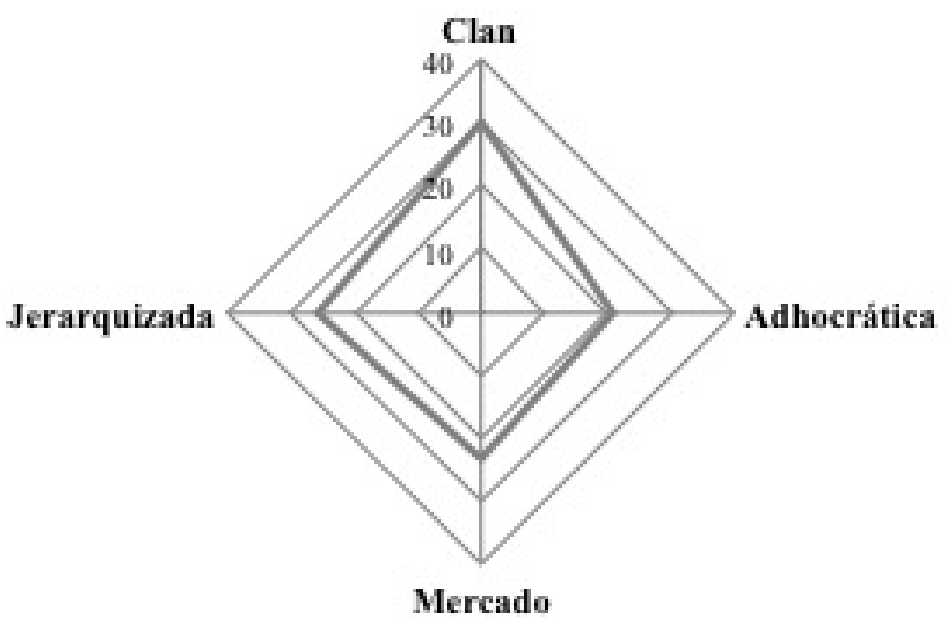

Figura 17. Resultados de la categoría: Unión de la organización.

\section{7.Énfasis estratégico}

De acuerdo con Cameron y Queen (1999), el énfasis estratégico en una cultura organizacional identifica las preferencias de la organización respecto de la confianza, apertura, participación, retos, competitividad, estabilidad y control. Al respecto se identificó que el énfasis estratégico se orienta principalmente hacia la Cultura Mercado (28\%), seguida de la Cultura Clan (25\%) y Jerarquizada (25\%). Esto significa que la mayoría de organizaciones enfatizan el desarrollo de acciones competitivas para ganar espacios en los mercados y que muchas de ellas promueven el desarrollo humano, fomentan la confianza, la apertura y la participación, así como la permanencia y la estabilidad. Son organizaciones donde la eficiencia, el control y la realización correcta del trabajo son importantes.

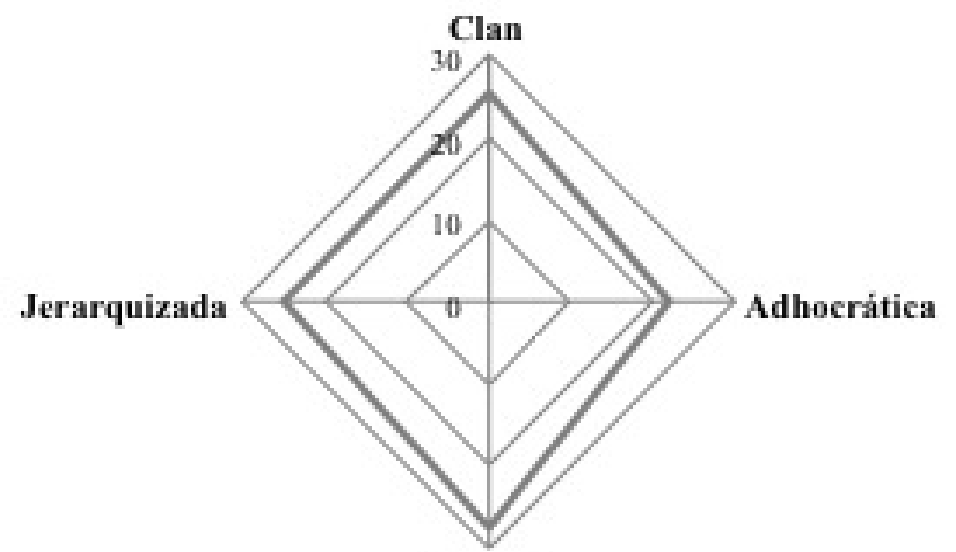

Mercado
Figura 18. Resultados de la categoría: Unión de la organizaciónz

\section{Criterios de éxito}

Los criterios para la definición del éxito en las organizaciones evaluadas se perfilan hacia el estilo de la Cultura Clan (29\%), seguida de la Cultura Jerarquizada (25\%). Lo anterior significa que la mayoría de las organizaciones definen el éxito sobre la base del desarrollo de los recursos humanos, el trabajo en equipo, las relaciones personales y el reconocimiento de las personas, así como en la eficiencia en el cumplimiento de sus tareas. 


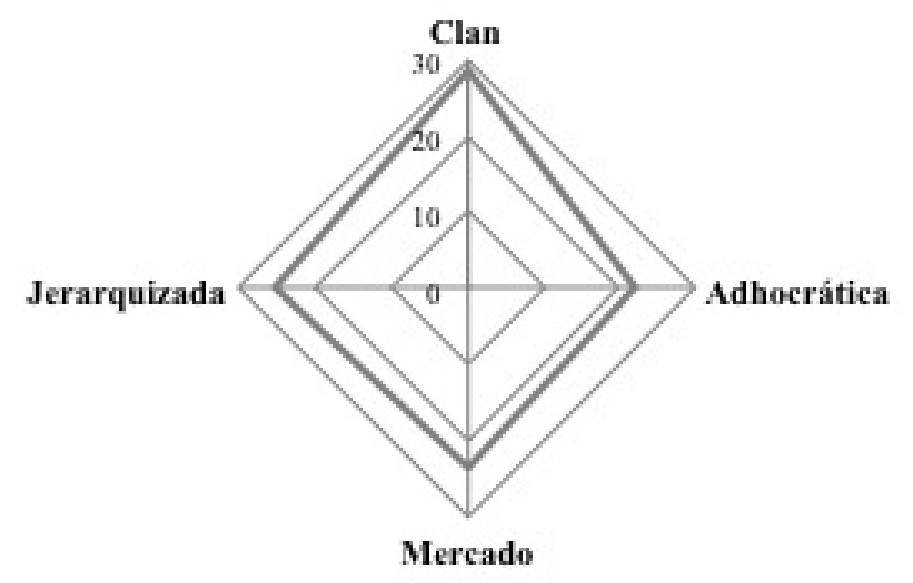

Figura 19. Resultados de la categoría: Criterios de éxito.

\section{Conclusiones y recomendaciones}

En todo el territorio mexicano y sin duda en el Valle del Mezquital, las MiPyMES se han constituido como generadoras de empleo y como detonadoras del desarrollo social y económico de esta región que, además de ser la más grande del Estado de Hidalgo, representa un tercio de la superficie de la entidad.

Es de particular relevancia que el tipo de servicios y productos que las MiPyMEs estudiadas generan, tiene relación directa con el aprovechamiento de los recursos naturales y la vocación agrícola, comercial y de servicios del Valle del Mezquital. El tiempo de operación y crecimiento que han tenido las empresas es variable, sin embargo destaca el hecho que más del $50 \%$ fue creada en los últimos 10 años, lo cual es signo de la importancia que han adquirido para la economía regional en las más recientes décadas, no obstante es preciso que los emprendimientos cuenten con rasgos de alto impacto para favorecer su permanencia y sobre todo para incrementar el impacto social y medioambiental en una región que históricamente se ha distinguido justamente por la pobreza de la mayoría de sus habitantes y por el detrimento de su ecología.

En ese sentido, el análisis del perfil de la or- ganización para el emprendimiento de alto impacto que este estudio incorporó con base en la propuesta de Ernst \& Young (2012), permitió identificar que los principales rasgos que distinguen a las organizaciones evaluadas son su orientación hacia la resolución de necesidades de sus clientes, la innovación, la simplicidad, así como el uso de la tecnología y el fomento de la colaboración. Estas características constituyen atributos que podrán facilitar a las organizaciones incursionar en el emprendimiento de alto impacto; sin embargo, requieren mejorar para ello su rentabilidad y su orientación a la satisfacción de necesidades en el marco de nuevas tendencias sociales y tecnológicas. De igual manera será preciso que incrementen su multidisciplinariedad, ya que esta es una condición en la que las organizaciones aun no muestran fortaleza suficiente para orientarse al emprendimiento de alto impacto.

En cuanto a las características y atributos asociados a los emprendedores de alto impacto analizados, fue posible identificar que en la mayoría de los casos, las empresas surgieron por el deseo personal del emprendedor por tener su propio negocio y que se han mantenido gracias a la pasión que depositan en su emprendimiento. Para ello, el establecimiento de una visión personal y el énfasis en transmitir a los colaboradores la pasión por el crecimiento del emprendimiento, han sido determinantes para la creación y evolución de las MiPyMEs, destacando la importancia que para los emprendedores han tenido: la actitud, la tolerancia al fracaso y el liderazgo. Una condición clave identificada para la consolidación y crecimiento de estas MiPyMEs es el autocontrol, ya que muchas iniciaron con financiamiento personal.

Sin embargo, para incrementar el alineamiento hacia el emprendimiento de alto impacto es preciso que los emprendedores muestren mayor resiliencia y aprovechen su experiencia y formación profesional a favor de la consolidación de sus empresas, dado que estos 
atributos han sido reconocidos por diversos autores como condiciones clave para favorecer el emprendimiento de alto impacto.

En el análisis de la comunicación en las organizaciones, se identificó un clima de apertura que resulta propicio para esta relevante actividad; la comunicación interna refleja el compromiso con el logro de los objetivos y la claridad de los mensajes por parte de la dirección, así como la diversidad de medios de comunicación utilizados al interior de las organizaciones, fueron los aspectos que demostraron mayor fortaleza. Sin embargo, se requieren más mecanismos de retroalimentación para expresar las quejas y sugerencias por parte de los clientes y sobre todo mejorar la efectividad y agilidad de los medios de comunicación que actualmente utilizan.

Respecto del clima organizacional, si bien el respeto de los trabajadores hacia sus autoridades y las buenas relaciones que se han logrado entre ellos para un trabajo productivo, son fortalezas que presentan las organizaciones, es preciso incrementar las oportunidades de crecimiento ya que este aspecto puede afectar el clima de la organización. En cuanto a la existencia de símbolos, rituales y creencias en las organizaciones, fue posible identificar que las creencias sobre el trabajo en la empresa son compartidas y que estas reflejan la convicción en el cumplimiento de los objetivos.

Para fortalecer este aspecto, se promueve la existencia de símbolos y signos que fortalezcan la imagen de las organizaciones, tales como el uso de uniformes o insignias. Será necesario, para el logro de mayor cohesión, favorecer la existencia de celebraciones o ceremonias que distingan la vida de las organizaciones y promover la participación de todos los miembros de la organización.

El establecimiento de acuerdos para la resolución de conflictos y la apertura que muestran los directivos para las propuestas de cambio y para la innovación, son las principales fortalezas del estilo directivo.

Sin embargo, es preciso mejorar la puntualidad de la información respecto de los cambios, así como clarificar las expectativas que los directivos tienen respecto a sus colaboradores, Existen importantes deficiencias en cuanto al reconocimiento público del buen desempeño, no obstante que la percepción de que existe de una asignación equitativa de estímulos al desempeño, es positiva. Las empresas cuentan con prestaciones adicionales al sueldo y en la generalidad, los estímulos establecidos para reconocer el desempeño ha resultado motivantes para el personal.

En la mayoría de las empresas existe normatividad que regula las actividades de la organización, pero se requiere mejorar la aplicación y difusión permanente de los reglamentos internos. De igual manera, existen estrategias de capacitación para la mayoría del personal, las cuales se llevan a cabo de forma equitativa. Sin embargo, la inexistencia de planes de desarrollo profesional para cada colaborador de la empresa constituye un aspecto que debería atenderse para mejorar el desempeño de la organización.

Por otra parte se ha identificado que en la mayoría de las organizaciones se tienen definidas las metas en el corto y mediano plazo, y que las actividades que se desarrollan se orientan al cumplimiento de dichas metas, sin embargo, se aprecia que no necesariamente cuentan con planes de trabajo para describir la manera en que alcanzarán sus objetivos. La mejora continua del equipamiento e instalaciones, es una de las fortalezas identificadas en el tema de gestión; no obstante la incorporación de tecnología no ha sido suficientemente atendida y se demandan procedimientos y programas de mejora de la calidad que permitan estandarizar las actividades.

A través de la aplicación del instrumento para determinar el tipo de cultura organizacional de acuerdo con el modelo Competing Val- 
ve Framework de Cameron y Quinn (1999); fue posible identificar que las características dominantes de la muestra evaluada se orientan hacia la cultura organizacional tipo Mercado, lo cual significa que, de manera general, las MiPyMEs se encuentran muy orientadas a los resultados y que su mayor preocupación es hacer un trabajo bien hecho.

En este marco, el liderazgo y el estilo gerencial se perfilan hacia el tipo de cultura Jerarquizada, lo cual indica que el liderazgo en las MiPyMEs es aprovechado para coordinar, organizar y mejorar la eficiencia; y que el estilo de manejo de los recursos humanos se caracteriza por dar seguridad de los puestos de trabajo y procurar la estabilidad en las relaciones humanas.

En cuanto a la unión de la organización, el tipo de cultura organizacional identificado, fue tipo Clan, lo cual indica que la lealtad y la confianza mutua mantiene unidas a las MiPyMEs. El énfasis estratégico, de las organizaciones evaluadas se encuentra alineado hacia el tipo de cultura Mercado, de esta forma, las MiPyMEs reconocen la importancia de promover acciones para incrementar su competitividad y ampliar con ello sus mercados.

Los criterios de éxito de las MiPyMEs identificados a través del modelo Competing Value Framework de Cameron y Quinn (1999); se encuentran alineados hacia el tipo de cultura Clan lo cual permite concluir que, si bien no existe un tipo de cultura único asociado a las MiPyMEs, esta organizaciones definen el éxito sobre la base del desarrollo de los recursos humanos, el trabajo en equipo, las relaciones personales y el reconocimiento de las colaboradores.

Si se consideran los resultados del estudio de caracterización de la cultura organizacional para impulsar el emprendimiento de alto impacto en el Valle del Mezquital, es posible establecer un conjunto de estrategias y recomendaciones, a fin de lograr un mayor alineamiento de las MiPyMEs hacia este tipo de emprendimiento y con ello, procurar un mayor impacto social de las mismas.

Enestesentido, las MiPyMES deben aprovechar en mayor medida la formación y experiencia de sus propietarios y emprendedores, atendiendo de manera especial aspectos tales como: desarrollar una adecuada planeación estratégica, favorecer la efectividad de la comunicación interna y externa, sistematizar y estandarizar sus procesos en un marco de calidad, incrementar el reconocimiento de los buenos resultados como medidas de motivación hacia el personal y favorecer el establecimiento de estrategias que aumenten el orgullo institucional y sentido de pertenencia, aprovechando el ejemplo y la pasión que los emprendedores depositan en sus organizaciones

Es muy destacable que para lograr una mejor alineación hacia el emprendimiento de alto impacto, las organizaciones deberán contar con rasgos preferentes en cuanto a su tipo de cultura organizacional, en este sentido se proponen un conjunto de recomendaciones que pueden contribuir a incrementar el impacto social de las MiPyMEs:

Retroalimentar a las organizaciones participantes sobre los resultados obtenidos para que puedan reconocer su tipo de cultura organizacional dominante, sus rasgos culturales y aprovechar este conocimiento para mejorar su alineación hacia el emprendimiento de alto impacto.

Promover el desarrollo de estrategias de vinculación y colaboración entre las MiPYMES y las instituciones de educación superior regionales para generar acciones específicas que detonen el emprendimiento de alto impacto en estas empresas.

Orientar las incubadoras tradicionales existentes en las instituciones de Educación Superior al emprendimiento de alto impacto para que las nuevas iniciativas emprendedoras sean perfiladas no solo a la búsqueda de un beneficio económico sino de un verdade- 
ro impacto social.

Fortalecer el trabajo colaborativo al interior de las organizaciones y el establecimiento de redes o alianzas de cooperación con otras MiPyMEs para promover la creación de cadenas productivas,

Favorecer la multidisciplinariedad en las MiPyMEs, eligiendo diferentes perfiles profesionales para enriquecer y diversificar los procesos productivos y de comercialización

- Asegurar la rentabilidad como una condición sine qua non para la permanencia de la empresa, a través de un cuidadoso control financiero.

- $\quad$ Aprovechar ampliamente los recursos tecnológicos disponibles para primer una mayor competitividad y elevar el grado de atracción de los productos y servicios que la MiPyME ofrece.

- Incursionar, si aun no se ha intentado, en la búsqueda de nichos de mercado en otras regiones del país y preferentemente en otros países aprovechando la conectividad informática y las redes logísticas y de distribución al servicio de las MiPyMEs.

- Alinear los procesos clave de las MiPYMES hacia un desarrollo sustentable, buscando no solamente una permanencia basada en el desempeño económico, sino asegurando el cuidado de los recursos naturales y del entorno ecológico por parte de la organización; y contribuyendo, a través de sus actividades, a elevar la calidad de vida de las comunidades en las que se encuentran asentadas las empresas.

- $\quad$ Promover la innovación como un estilo de trabajo y una permanente oportunidad de negocio para la empresa, reconociendo e impulsando las ideas de todos los colaboradores para mejorar o crear nuevos procesos, productos y servicios.

- Aprovechar las tendencias sociales y tecnológicas para incrementar y diversificar la oferta de productos y servicios que atiendan necesidades emergentes de la po- blación y que aprovechen la tecnología y la globalidad.

- $\quad$ Asegurar que las actividades de las MiPyMEs generen un impacto social positivo y que creen valor no solo para sus clientes, sino también para sus proveedores, para sus colaboradores, para sus propietarios y para la comunidad en la que se encuentren establecidas.

Finalmente, puede concluirse que mediante la identificación de los rasgos culturales y del tipo de cultura organizacional, es posible comprender y gestionar mejor la cultura de las MiPyMEs buscando propiciar condiciones que contribuyan a lograr un mejor alineamiento hacia el emprendimiento de alto impacto. El presente estudio constituyó un primer acercamiento al análisis de la cultura organizacional asociada con el emprendimiento de alto impacto en la región del Valle del Mezquital, y dada la relevancia que las MiPyMEs tienen en esta zona, es muy recomendable ampliar en el futuro nuevas líneas de investigación se centren en la búsqueda de estrategias para incrementar la permanencia, el desempeño, la competitividad y impacto social de este tipo de organizaciones. 
Barney, J. (1991) Firm resources and sustained competitive advantage. Journal of Manage-ment. 17 (1) 99-120, 1991, https://doi.org/10.1177/014920639101700108 Belausteguigoitia, I. (2006) Empresas Famili-ares, Su Dinámica, Equilibrio y Consolidación. 2a ed. México: Mc Graw Hill, 2006.

Buenaventura, P. (1995). Dirigir el cambio de la cultura organizacional hacia la calidad total.

Cuadernos de Ciencias Económicas y

Empresariales, 28, pp. 11-18.

Cameron, K. y Quinn, R. (1999). Diagnosing and Changing Organizational Culture. Addi-son-Wesley Series. New York

CDI (2009) Otomíes del Valle del Mezquital -Hñä hñü. Monografias . Comisión Nacional para el Desarrollo de los Pueblos Indigenas. México. CONAPO (2011) Índice de marginación por entidad federativa y municipio 2010. Consejo

Ernst \& Young (2012) Nature or nurture? Decoding the DNA of the Entrepreneur.

Esparza, J; García, D. y Gómez, A. (2010) La cultura empresarial en la gestión de las empresas familiares: Una aproximación teórica. Investigación y ciencia. Universidad Autónoma de Aguascalientes. Hellriegel, D. y Slocum, J. (2009). Comportamiento Organizacional. 12 ${ }^{\mathrm{a}}$. Ed. México: Cengage.

Hernández, R. (2006) Metodología de la Investigación. México. Ed. Mc-Graw Hill. Cuarta Edición.

INEGI. (2010). Resumen de los resultados de los Censos Económicos 2009. Instituto Nacional de Estadística y Geografía. México.

INEGI (2009). Estratificación de los establecimientos. Instituto Nacional de Estadística y Geografía. México.

Koiranen, M. (2002) Over 100 Years of Age But Still Entrepreneurially Active in Business: Exploring the Values and Family Characteristics of Old Finnish Family Firms. Family Business Review, XV (3): 175188, 2002,

https://doi.org/10.1111/j.1741-6248.2002.00175.x Lozano, C. (2013) Emprendimiento de Alto Impacto. Facultad de Ciencias Económicas. Universidad de Nueva Granada. Colombia.
Martínez, E. y Robles, C. (2009). Cultura organizacional en el sistema de gestión de calidad en las de-pendencias de educación superior del Valle de México. Revista Gestión y Estrategia, 2(36), pp. 54-65.

Martínez, M., Gómez. M; Rosés, S; y García, R. (2014) Gestión creativa de las Start-ups. Editorial Netbiblio. España.

Martínez, P., Gallegos, J., Alonso, P; Almanza, L; y Rodríguez, L. (2014) Emprendedores de Alto Impacto. Laboratorio Emprendedor. México.

Maull, R; Brown, P. y Cliffe, R. (2001). Organizational culture and quality improvement. International Journal of Operations \& Production Management, 21(3), 302-326,

https://doi.org/10.1108/01443570110364614

Mendoza, J; Hernández, M; y Salazar, B. (2010). Las PYMES familiares y no familiares $¿$ Empresas diferentes?. Universidad Autónoma del Estado de Hidalgo.

Robbins, S. y Judge, T. (2009). Comportamiento Organizacional. 13 Ed. México: Pearson Educación.

Romero, L. (2006) Competitividad y productividad en empresas familiares PyMES. Una aproximación desde la interacción familia-empresa. Revista EAN No. 57 mayo-agosto de 2006 p.131-142,

https://doi.org/10.21158/01208160.n57.2006.378 Rizo, M. (2014) Pymes en México, fuente principal de empleos. El Semanario Sin Límites. Marzo 2014. Schein, E. (2010) Organizational Culture and Leadership. 4th Ed. USA: Wiley.

Toca, C. y Carrillo, J. (2009). Asuntos teóricos y metodológicos de la cultura organizacional. Revista Civilizar, 9(17), pp. 117-136,

https://doi.org/10.22518/16578953.711

Ward, J. (2005). Unconventional wisdom. Counterintuitive insights for family business sucess. Chichester, England, John Wiley \& Sons Ltd.

Zahra, S.; Hayton, J. y Salvato, C. (2004), Entrepreneurship in family vs. non-family firms: a re-source-based analysis of the effect of organization-al culture. Entrepreneurship Theory \& Practice, 28 (4): 363-81, 2004,

https://doi.org/10.1111/j.1540-6520.2004.00051.x 
Copyright (c) 2016 Irasema Linares Medina, Julio Márquez Rodríguez y Esther Botho Clemente

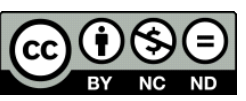

Este texto está protegido por una licencia Creative Commons 4.0.

Usted es libre para Compartir (copiar y redistribuir el material en cualquier medio o formato), siempre que cumpla las condiciones de:

Atribución: Usted debe dar crédito a la obra original de manera adecuada, proporcionar un enlace a la licencia, e in dicar si se han realizado cambios. Puede hacerlo en cualquier forma razonable, pero no de forma tal que sugiera que tiene el apoyo del licenciante o lo recibe por el uso que hace de la obra.

No Comercial: Usted no puede hacer uso de la obra con propósitos comerciales

Sin Derivadas: Si remezcla, transforma o crea a partir de la obra, no podrá distribuir la obra modificada

Resumen de la licencia - Texto completo de la licencia 